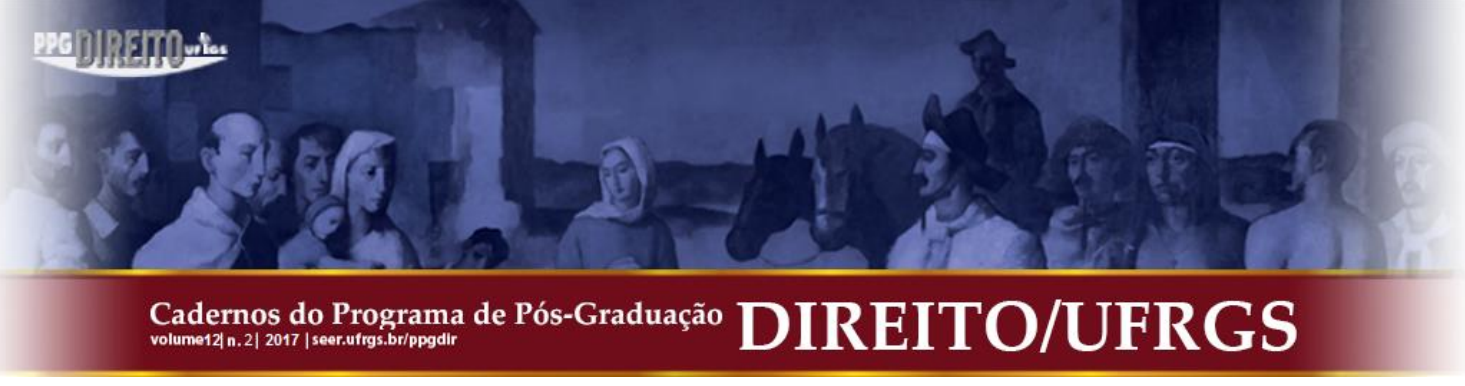

\title{
DELIBERAÇÃO INTERNA E LEGITIMAÇÃO DAS CORTES SUPREMAS
}

\author{
INTERNAL DELIBERATION AND SUPREME COURTS' LEGITIMACY
}

\author{
Bruno Meneses Lorenzetto* \\ Letticia de Pauli Schaitza**
}

\begin{abstract}
RESUMO: O artigo parte da superação da concepção estática de separação de poderes e critica os argumentos normalmente utilizados para justificar a legitimidade das Cortes Supremas para rever atos do Poder Legislativo por ignorarem que os juízes não decidem em um vácuo institucional e que a interação com seus pares influencia na tomada da decisão. Dessa forma, através da exposição dos modelos legal, atitudinal e estratégico, explicativos da tomada de decisão judicial, apresenta as Cortes não apenas como interlocutoras externas, mas sobretudo como tribunais colegiados deliberativos, a fim de enfatizar a importância da deliberação colegiada para a legitimidade da jurisdição constitucional e a qualidade da sua performance.
\end{abstract}

PALAVRAS-CHAVE: Legitimação Jurisdicional. Deliberação. Cortes Supremas.
ABSTRACT: The article assumes the overcoming of the static conception of the separation of powers and criticizes the arguments normally used to justify the legitimacy of the Supreme Courts to review acts of the Legislative Power to the extand that they ignore that the judges do not decide in an institutional vacuum and that the interaction with their peers influences in the decision making process. Thus, through the exposition of legal, attitudinal and strategic judicial decision-making models, it presents the Courts not only as external interlocutors, but above all as collegiate deliberative tribunals, in order to emphasize the importance of collegial deliberation to constitutional jurisdiction legitimacy and the quality of its performance.

KEYWORDS: Jurisdictional Legitimacy. Deliberation. Supreme Courts.

SUMÁRIO: Introdução. 1 A Nova Configuração do Princípio da Separação dos Poderes e a Legitimação da Corte Constitucional. 2 Cortes Supremas como "Deliberadores Internos": a Deliberação em um Tribunal Colegiado. Considerações Finais. Referências.

\section{INTRODUÇÃO}

A maneira pela qual os poderes Legislativo e Judiciário interagem é contingencial, isto é, altera-se de acordo com diferentes fatores, como a história constitucional e o desenho institucional de um determinado contexto. Fato é, porém, que as fronteiras entre legislação e jurisdição são cada vez mais tênues. Isso se dá, sobretudo em razão da judicialização de questões, em princípio, políticas e do reconhecimento de que a norma não está implícita no texto legal e, por isso, a atividade legislativa necessita da atividade interpretativa dos juízes. ${ }^{1}$

\footnotetext{
* Doutor em Direito pela Universidade Federal do Paraná (UFPR). Professor de Direito da Pontifícia Universidade Católica do Paraná (PUC-PR). Coordenador do Programa de Mestrado em Direito e Professor da Graduação do Centro Universitário Autônomo do Brasil (UniBrasil), Paraná. Visiting Scholar na Columbia Law University, Estados Unidos.

** Mestranda em Direito das Relações Sociais pelo Programa de Pós-Graduação em Direito da Universidade Federal do Paraná (UFPR). Integrante do Núcleo de Pesquisa em Direito Processual Civil Comparado da Universidade Federal do Paraná (UFPR).

1 "Não existe norma que esteja distanciada da operação hermenêutica. A produção de normas e de seus sentidos são atividades que precisam da interpretação, ou seja, para que possam ter força normativa, força de lei, elas demandam alguém com autoridade para dizer qual é a lei para a situação em disputa. Disso se depreende que os 


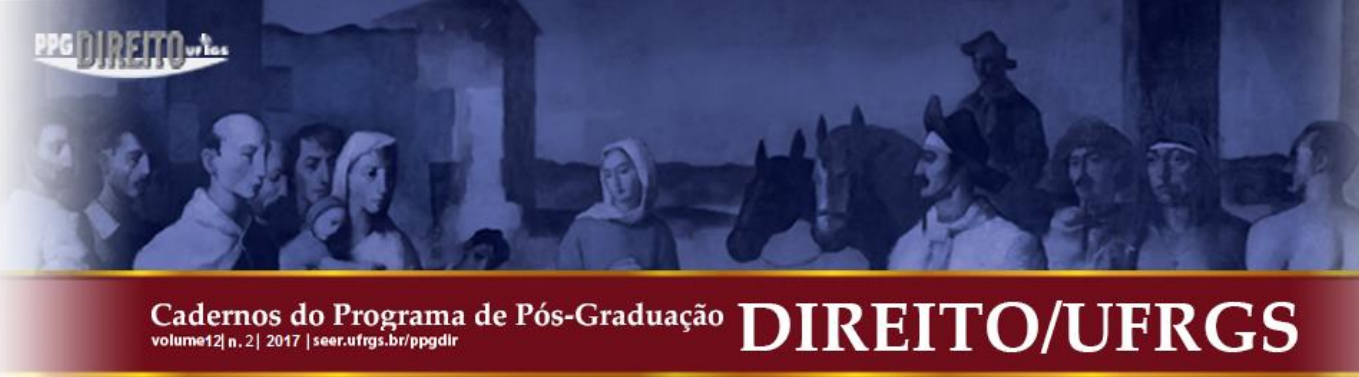

No entanto, na medida em que os membros das Cortes Supremas Constitucionais, isto é, dos tribunais jurisdicionais de vértice responsáveis pela revisão dos atos do Poder Legislativo a partir da interpretação da Constituição, via de regra, não são eleitos democraticamente, questiona-se sua legitimidade. Os principais argumentos utilizados para justificar a legitimidade da jurisdição constitucional - capacidade de proteger os direitos das minorias, de apresentar as "melhores razões" e de catalisar o diálogo interinstitucional -, no entanto, ignoram, muitas vezes, a dimensão dialógica interna dos tribunais colegiados, fundamental para conferir qualidade à sua atuação. Em outras palavras, não se aprofundam na dinâmica interna através da qual a Corte, na qualidade de instituição colegiada, constrói sua decisão.

Diante disso, este artigo, em um primeiro momento, revisa as principais justificativas responsáveis por legitimar a crescente intervenção do Poder Judiciário em questões jurídicas e políticas para, em seguida, legitimá-la sob um viés interno e deliberativo. Para tanto, analisa-se a forma como os juízes de tais tribunais se comportam internamente, persuadem-se e apresentam suas razões entre si, apontando-se, além disso, fatores externos capazes de influenciá-los, a partir da exposição dos modelos legal, atitudinal e estratégico, explicativos da tomada de decisão judicial.

Argumenta-se, através da revisão de bibliografia principalmente norte-americana, que o potencial deliberativo das Cortes depende de rodadas deliberativas internas e externas, cuja qualidade pressupõe não apenas um desenho institucional favorável, como também o compartilhamento de um ideal de deliberação e de uma concepção de papel institucional.

\section{A NOVA CONFIGURAÇÃO DO PRINCÍPIO DA SEPARAÇÃO DOS PODERES E A LEGITIMAÇÃO DA CORTE CONSTITUCIONAL}

Em uma democracia constitucional o poder se encontra repartido a fim de evitar o desenvolvimento de governos tirânicos e autoritários. Tal sistema de checks-and-balances tem sua origem em $\mathrm{O}$ Federalista $^{2}$, mas hoje se apresenta sob nova roupagem, mais flexível e maleável. Reconhece-se, atualmente, a interação necessariamente dinâmica entre os poderes

dispositivos que serão interpretados, em princípio, terão como resultado uma norma" (CLÈVE, Clèmerson Merlin; LORENZETTO, Bruno Meneses. Interpretação constitucional: entre dinâmica e integridade. Revista Sequência, n. 72, 2016, p. 70).

2 Ver: HAMILTON, A.; MADISON, J.; JAY, J. The Federalist Papers. New York: Signet Classics, 2003; LIMONGI, Fernando Papaterra. "O Federalista": remédios republicanos para males republicanos. In: WEFFORT, Francisco (Org.). Os clássicos da política. v. 1. São Paulo: Ática, 2000. 


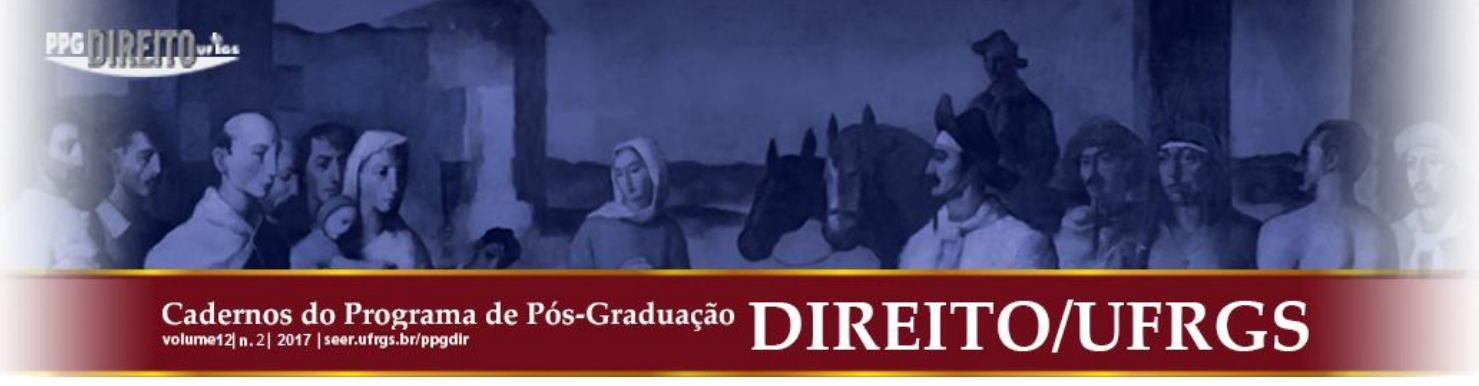

Legislativo, Executivo e Judiciário, variável não apenas de acordo com o desenho institucional no qual estão inseridos, ${ }^{3}$ mas também, conforme a dinâmica dos agentes envolvidos e da história constitucional existente.

José Rodrigo Rodriguez salienta que o núcleo normativo próprio da democracia é justamente o princípio segundo o qual a dinâmica institucional é adaptável a variadas conjunturas. ${ }^{4}$ Dessa forma, não é possível a prévia definição acerca do papel a ser ocupado pelo Poder Judiciário na repartição de competências, cabendo a este ser construído e (re)delineado constantemente. ${ }^{5}$

Diante disso, só faz sentido falar em "ativismo judicial" quando se toma como padrão uma teoria normativa da política fundada numa noção estática de separação de poderes. Consequentemente, na atualidade, são menos definidas as fronteiras entre legislação e jurisdição, entre política e direito. Não se pode mais negar sua intrínseca e inevitável relação. ${ }^{6}$ Barroso admite que o juiz não faz escolhas livres tampouco suas decisões são estritamente políticas. ${ }^{7}$ É certo que o Judiciário assumiu novo papel em relação ao Legislativo, a partir do qual passou a regular a atividade parlamentar por meio da imposição de restrições substantivas ao processo legislativo através do controle de constitucionalidade e a interferir na própria atividade política mediante a limitação do comportamento de grupos de interesse, partidos e agentes políticos. ${ }^{8}$

\footnotetext{
3 "Um desenho institucional consiste na alocação de faculdades de estatuir e da faculdades de vetar em diferentes agentes. Entre vetos e estatuições, desenha-se um processo decisório, distribuem-se poderes, moldam-se incentivos institucionais, criam-se canais saudáveis de interlocução. Numa sucessão de testes, uma decisão coletiva finalmente é tomada. (...) O controle de constitucionalidade seria uma veto a mais na intrincada rede das faculdades de vetar e estatuir que compõe a engenharia da separação de poderes" (MENDES, Conrado Hübner. Controle de Constitucionalidade e Democracia. Rio de Janeiro: Elsevier, 2008, p. 132).

${ }^{4}$ RODRIGUEZ, José Rodrigo. Como decidem as cortes? Para uma crítica do direito brasileiro. Rio de Janeiro: Editora FGV, 2013, p. 188.

${ }^{5}$ RODRIGUEZ, José Rodrigo. Como decidem as cortes? Para uma crítica do direito brasileiro. Rio de Janeiro: Editora FGV, 2013, p. 199.

6 "Judicial review can be understood as attractive precisely because it is embedded in politics, but is not quite of it. Politics and law are not separate, they are symbiotic. It would be remarkable to believe judicial review could operate entirely independent of politics or would be tolerated as such. Nor is it clear that this would be desireble given social and constitutional commitments to accountability and checks and balances. The practice of judicial review is valuble in that it serves as one more counterweight, like many others in our constitutional system. Moreover, because judicial decisions about constitutional law are sticky - they cannot be overturned at the drop of a hat - judicial review serves to channel and foster societal debate about constitutional meaning". (FRIEDMAN, Barry. The politics of judicial review. Texas Law Review, 84, 2, 2005, p. 333).

${ }^{7}$ BARROSO, Luís Roberto. As razões sem voto. Revista Brasileira de Políticas Públicas, v. 5, Número Especial, 2015 , p. 33

${ }^{8}$ CLĖVE, Clèmerson Merlin; LORENZETTO, Bruno Meneses. Constituição federal, controle jurisdicional e níveis de escrutínio. Direitos Fundamentais e Justiça, a. 9, n. 32, p. 97-123, jul./set. 2015, p. 103. 


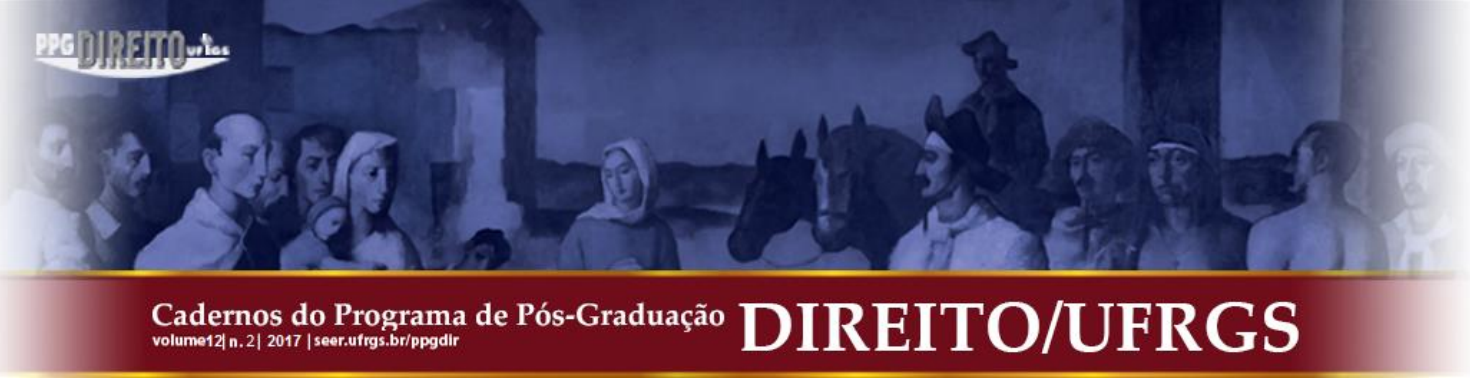

Ora, impera reconhecer que atividades podem ser compartilhadas de forma harmônica entre mais de um poder, o que, porém, não significa que serão desempenhadas da mesma maneira. Exemplo disso é o desenvolvimento do Direito. Partindo-se do pressuposto de que o juiz não se limita à aplicação de regras e à definição do exato sentido da lei, admite-se sua participação na criação normativa e, portanto, seu cunho criativo e político. ${ }^{9}$ Nesse ponto, reconhece-se a atribuição de fazer política à uma instituição não eleita democraticamente, o que, há muito, motiva os estudiosos a buscar uma justificativa de legitimação.

Afinal, onde residiria a legitimidade de poucos "iluminados" para sobrepor com suas decisões a vontade majoritária de representantes eleitos democraticamente? Basicamente, as objeções contra as Cortes podem ser classificadas em substantiva e procedimental. A primeira compreende a ideia de que as decisões legítimas numa democracia são as que refletem a vontade majoritária, que, por sua vez, seria representada apenas pelos poderes eleitos democraticamente, visto que submetidos a um controle popular periódico. Nessa visão, as Cortes, porque não compostas por representantes conclamados pela vontade popular, estariam imunes à accountability popular ${ }^{10} \mathrm{e}$, por isso, representariam um risco à própria democracia, não sendo legitimadas, portanto, a anular ou reconfigurar aquilo decidido e votado democraticamente pelos agentes eleitos. Procedimentalmente, a crítica reside justamente na ausência de processo democrático para a indicação dos juízes, via de regra. ${ }^{11}$

Em resposta a essa desconfiança, fundamenta-se a legitimação democrática do controle de constitucionalidade, substancialmente, em quatro proposições. Primeiramente, no reconhecimento de que a norma legislativa não está implícita no texto legal e dele difere. ${ }^{12}$ Consequentemente, precisa ser interpretada e (re)construída pelo juiz a partir de elementos textuais e extratextuais, o que não contradiz a atividade do legislador, mas a complementa. Em

\footnotetext{
${ }^{9}$ RODRIGUEZ, José Rodrigo. op. cit., p. 129.

${ }^{10}$ O’DONELL, Guilhermo. Accountability horizontal e novas poliarquias. Lua Nova, n. 44, 1998.

${ }^{11}$ FRIEDMAN, Barry. Dialogue and Judicial Review. Michigan Law Review, 91, 1993, p. 588. Há casos, porém, em que juízes são eleitos, como em alguns estados norte-americanos, nos quais são realizadas até mesmo campanhas eleitorais. A respeito das transformações recentes nesse tipo de processo eletivo ver: POZEN, David E. The Irony of Judicial Elections. Columbia Law Review, v. 108, n. 2, 2008; PAES, Alberto de Moraes Papaléo. Democracia, controle de constitucionalidade e direitos fundamentais - o novo centro de concentração do poder político. Revista de Direitos Fundamentais e Democracia, v. 17, n. 17, 2015, p. 77.

12 “(...) os diferentes modos pelos quais se faz possível realizar a construção semântica encontra, no âmbito jurídico, respaldo na orientação que determina a fundamentação das sentenças, a apresentação de razões por seus intérpretes com a finalidade de comunicar suas decisões para que estas possam ser compreendidas por seus destinatários." (CLÈVE, Clèmerson Merlin; LORENZETTO, Bruno Meneses. Teorias Interpretativas, Capacidades Institucionais e Crítica. Revista Direitos Fundamentais e Democracia, v. 19, n. 19, 2016, p. 134).

Cadernos do Programa de Pós-Graduação em Direito PPGDir./UFRGS | Edição Digital | Porto Alegre | Volume XII| Número 2 | 2017 | P. 281 - 306
} 


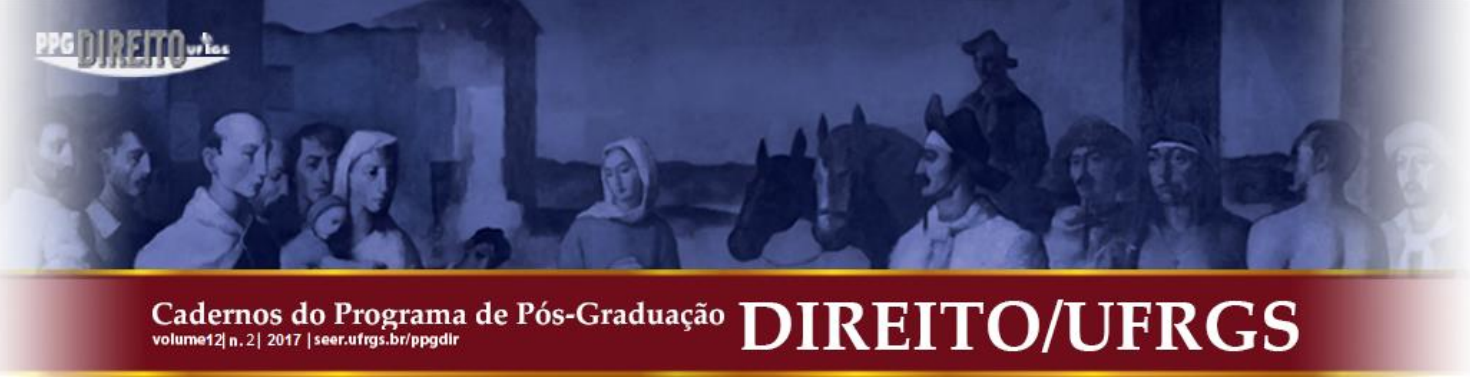

segundo lugar, no papel contramajoritário da Corte, isto é, na sua qualidade de integrante da dinâmica de checks and balances capaz de proteger a tutela dos direitos fundamentais e das minorias em face de eventual ditadura da maioria. Em terceiro lugar, na capacidade argumentativa da Corte de apresentar as "melhores razões" para a resolução de questões de princípio. Por fim, em sua aptidão para catalisar o diálogo interinstitucional entre as instâncias de poder.

No que diz respeito à primeira justificativa, importa reconhecer que a evolução da teoria da interpretação, o impacto do constitucionalismo e o emprego de cláusulas gerais transformaram o papel das Cortes ao reconhecer que o direito não é revelado pelo intérprete, mas (re)construído interpretativamente. Isso porque o texto legal pode sofrer indeterminações linguísticas como a vagueza e a ambiguidade, constituindo tarefa do operador do direito a realização de sua interpretação, de acordo não apenas com seu contexto, mas também, a partir de uma inafastável carga ideológica. ${ }^{13}$ A propósito, Daniel Mitidiero aponta que os enunciados textuais se caracterizam por inerente ambiguidade, complexidade, implicabilidade, superabilidade e abrangibilidade. ${ }^{14}$

Assim, o intérprete, ao realizar a interpretação do texto legal, é influenciado por diferentes interesses, concepções de justiça, concepções dogmáticas e métodos interpretativos, ${ }^{15}$ de modo a reconstruir, ao longo da história, o significado normativo dos textos legais, a partir de orientações lógico-argumentativas. Dessa forma, até mesmo o enquadramento de um caso como fácil ou difícil por si só pressupõe prévia valoração e interpretação, não se podendo falar anteriormente à decisão na existência de uma única resposta correta ou da resposta intentada pelo legislador originário, o que, no entanto, não significa que o processo de interpretação não possa - ou não deva - ser racionalmente controlado. ${ }^{16}$ Conforme pontua Luiz Guilherme Marinoni, “a decisão deixa de se situar no local da procura do 'sentido exato da lei'

\footnotetext{
${ }^{13}$ MARINONI, Luiz Guilherme. Precedentes obrigatórios. 3. ed. São Paulo: Ed. RT, 2013, p. 45.

14 "Os textos são potencialmente equívocos por várias razões. Dentre elas, a ambiguidade, a complexidade, a implicabilidade, a superabilidade e a abrangibilidade dos enunciados textuais. Os enunciados são ambíguos, porque apresentam duas ou mais opiniões de significado. São complexos, porque podem exprimir duas ou mais normas ao mesmo tempo. Por vezes, pode existir dúvida a respeito da existência de um nexo de implicação entre os enunciados, da superabilidade ou não do enunciado - isto é, se ele está sujeito ou não a exceções implícitas - e da abrangência da disposição - se taxativa ou meramente exemplificativa. Em todos esses casos, o texto pode revelar-se equívoco e é necessário individualizar, valorar e escolher entre duas ou mais opções de significado a fim de obter-se uma norma." (MITIDIERO, Daniel. Cortes Superiores e Cortes Supremas. 2. ed. São Paulo: Ed. RT, 2014, p. 55.)

${ }^{15}$ MITIDIERO, Daniel. op. cit., p. 55.

16 MITIDIERO, Daniel. op. cit., p. 59.
}

Cadernos do Programa de Pós-Graduação em Direito PPGDir./UFRGS | Edição Digital | Porto Alegre | Volume XII| Número 2 | 2017 | P. 281 - 306 


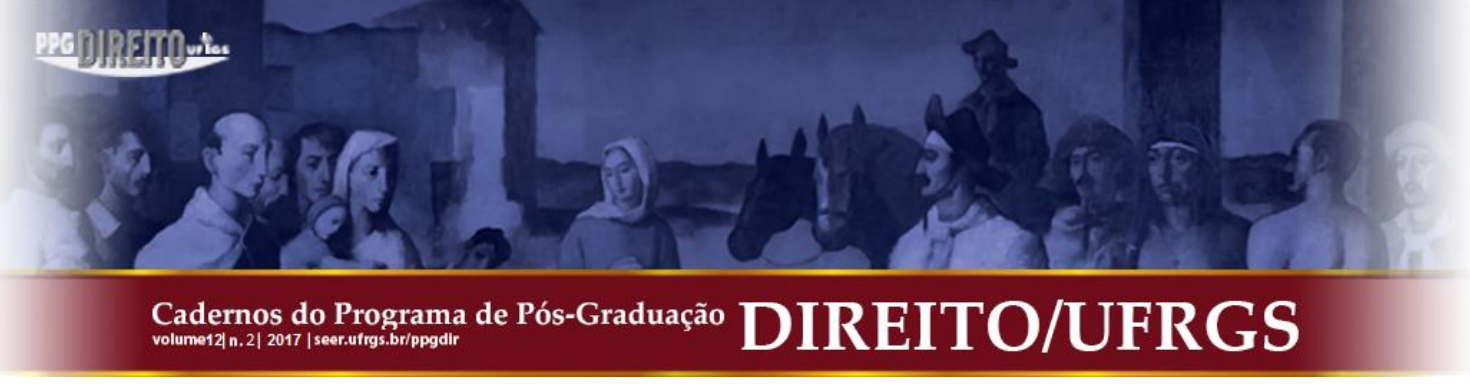

e passa a ocupar o lugar da justificativa das opções interpretativas, ou seja, da racionalidade da interpretação". ${ }^{17}$ Uma vez reconhecido o direito como interpretação e prática argumentativa, reconhece-se a autonomia da decisão diante da lei.

Passa-se, portanto, de uma concepção de Corte de Cassação responsável pelo controle de legalidade para a ideia de uma Corte Suprema cuja função é a atribuição de sentido ao direito e a tutela da igualdade através da elaboração de precedentes. ${ }^{18}$ Reconhece-se que as Cortes de Vértice agregam conteúdo à ordem jurídica e, por isso, não mais apenas o dispositivo das suas decisões importam, mas sobretudo suas razões de decidir. No entanto, especialmente no Brasil e em geral nos países de civil law, em diferentes graus, ainda se reproduz um modelo formalista de interpretação jurídica que concebe os tribunais constitucionais como um "terceiro grau de jurisdição". Despreza-se a função da Corte de orientação proativa do direito através de precedentes, realizando-se uma atividade reativa. ${ }^{19}$

Em segundo lugar, no tocante à legitimação da Corte em razão da sua função contramajoritária $^{20}$, assinale-se que no Brasil, assim como em diferentes lugares do mundo, verifica-se uma crise de representação política. Isso implica reconhecer a "inevitável dificuldade de o sistema representativo expressar, efetivamente, a vontade majoritária da população". ${ }^{21}$ Trata-se, para Barroso, de um fenômeno de certa forma universal, caracterizado pelos "desmandos do financiamento eleitoral, a indesejável infiltração da religião no espaço público e a radicalização de alguns discursos partidários" ${ }^{22}$, responsáveis por depreciar o debate público e distanciar o cidadão comum.

Logo, admitir que os poderes Legislativo e Executivo têm mais accountability e são mais legítimos que o Poder Judiciário tão somente porque eleitos democraticamente constitui um argumento frágil. ${ }^{23}$ Isso porque tampouco as instâncias políticas são capazes de veicular em

\footnotetext{
${ }^{17}$ MARINONI, Luiz Guilherme. op. cit., 2013, p. 39.

${ }^{18}$ MARINONI, Luiz Guilherme. op. cit., 2013, p. 24.

${ }^{19}$ TARUFFO, Michele. Processo civil comparado: Ensaios. São Paulo: Marcial Pons, 2013.

${ }^{20}$ Lembre-se que Alexander Bickel afirma que o compromisso com o ideal majoritário não pode ser absoluto. BICKEL, Alexander. The Least Dangerous Branch: the Supreme Court at the Bar of Politics. New Haven: Yale University Press, 1986.

${ }^{21}$ BARROSO, Roberto. op. cit., p. 38.

22 BARROSO, Roberto. op. cit., p. 38.

${ }^{23}$ Para Alec Stone Sweet: "Separation of powers doctrines help those who govern (e.g. government ministers, members of parliament, judges, and administrators) make sense of their own role in the political system, and of how they are expected to interact with other actors. They thus constitute not only models of the polity, but models of action. To the extent that these models actually condition how governmental actors take decisions, they deserve our attention. Today, judges and legislators not only participate in constitutional politics, but their works is deeply impacted by the evolution of constitutional rules, and these behaviours are not modeled well by traditional 


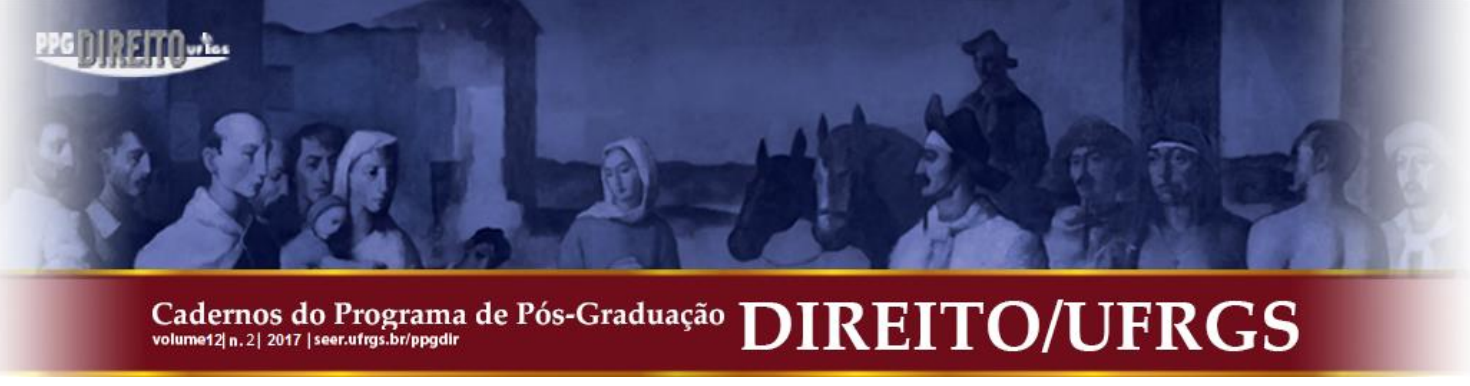

sua plenitude a vontade majoritária, seja em razão da dificuldade em identificá-la, da deficiência do sistema eleitoral e partidário, dos problemas advindos do presidencialismo de coalizão (sobretudo no Brasil), ${ }^{24}$ dos vetos das minorias, dos interesses de agentes externos à política ou do próprio autointeresse dos representantes populares. ${ }^{25}$ É nesse sentido que Corinna Lain demonstra que Cortes Constitucionais podem funcionar como instâncias majoritárias em face de parlamentos não representativos. ${ }^{26}$

Alec Stone Sweet, por seu turno, afirma que as Cortes constitucionais precisam, obrigatoriamente, justificar suas decisões de forma escrita, mas tal imposição está relacionada com sua busca por legitimação, de maneira que, neste ambiente institucional, os magistrados procuram não apenas fazer com que o controle de constitucionalidade sobreviva, mas, prospere; ou seja, buscam reconstruir o ambiente em que se mantenha a vitalidade do controle de constitucionalidade e isso só pode ocorrer com a atração de outros atores políticos para o discurso da adjudicação, ainda, as Cortes precisam convencer suas audiências de que o seu exercício de poder é limitado de maneira significativa pelo processo de raciocínio normativo, leia-se, não se trata de o uso de um poder arbitrário. ${ }^{27}$ Compreende-se, do exposto, que a accountability advinda do Judiciário se aloja em outros setores distintos do processo eleitoral, está no plano da justificação, das razões e dos limites que conduziram o processo decisório e na preocupação com a manutenção da legitimidade dos instrumentais para realizar o controle de constitucionalidade.

No tocante aos déficits do processo eleitoral, por exemplo, além das controvérsias relacionadas ao financiamento privado das campanhas - que absorve os interesses de elites e classes dominantes ${ }^{28}$-, o voto em um determinado candidato dá-se geralmente de acordo com

separation of powers doctrines."(SWEET, Alec Stone. Governing With Judges: constitutional politics in Europe Oxford: Oxford University Press, 2000, p. 130-131).

${ }^{24}$ CLÈVE, Clèmerson Merlin. Presidencialismo de coalizão e administração pública. In: CLÈVE, Clèmerson Merlin (Coord.). Direito Constitucional Brasileiro: organização do estado e dos poderes. v. 2. São Paulo: Revista dos Tribunais, 2014; SCHIER, Paulo Ricardo. Presidencialismo de Coalizão: democracia e governabilidade no Brasil. Revista Direitos Fundamentais e Democracia. v. 20, n. 20, 2016.

${ }^{25}$ BARROSO, Roberto. op. cit., p. 39.

${ }^{26}$ Segundo a autora, "Political polarization, monied special interests, voting deficiencies, veto gates - there are a number of forces that push democratic decision making away from majoritarian outcomes, just as there are a number of forces that push Supreme Court decision making the opposite way" (LAIN, Corinna Barrett. UpsideDown Judicial Review. The Georgetown Law Journal, v. 101:113, 2012, p. 115-116). Outro fator apontado pela autora é a possibilidade de determinados grupos com peculiares tendências estejam subrepresentados politicamente (como mulheres nos Estados Unidos), de modo que suas preferências não são representadas devidamente.

${ }^{27}$ SWEET, Alec Stone. op. cit., p. 144.

${ }^{28}$ Para Jaramillo, "El elegido no se siente comprometido con quienes lo eligieron sino con quienes financiaron su campaña. Dentro de esta lógica perversa se contribuye a su vez a agravar otras falencias de las democracias

Cadernos do Programa de Pós-Graduação em Direito PPGDir./UFRGS | Edição Digital | Porto Alegre | Volume XII | Número 2 | 2017 | P. 281 - 306 


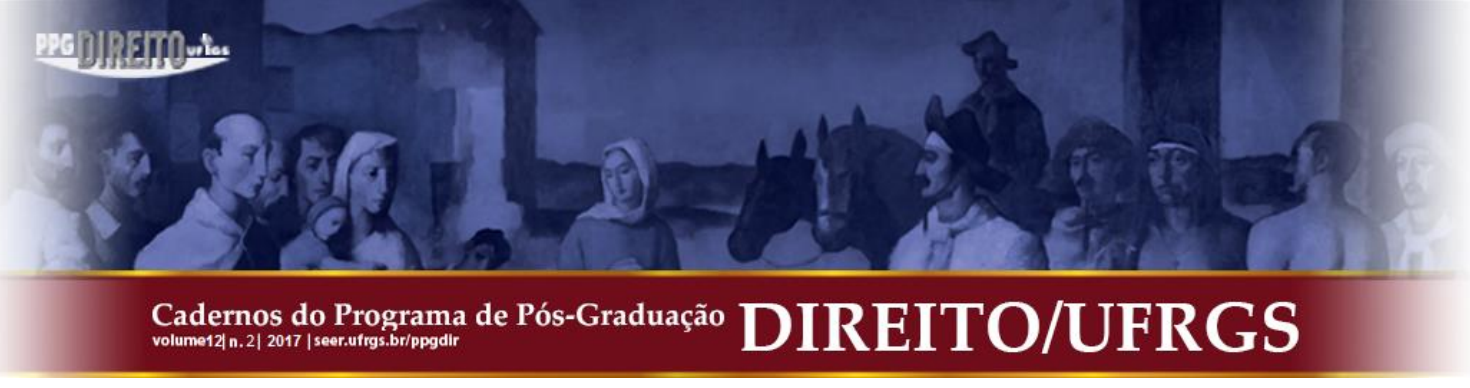

o "pacote" de propostas por ele apresentado. Vale dizer, vota-se em um determinado representante muitas vezes por afinidade ideológica e até em razão do partido do qual faz parte, o que significa que não necessariamente há identificação com todas as suas orientações, ainda mais naquilo considerado moralmente controvertido. ${ }^{29}$ A propósito, Leonardo Garcia Jaramillo pontua que os progressos alcançados na democracia eleitoral não contribuíram para o desenvolvimento de uma democracia real, capaz de garantir os direitos políticos mínimos, ${ }^{30}$ visto que se coopta, muitas vezes, por interesses políticos sectários, empresariais e forças de mercado. $^{31}$

Assim, a crescente intervenção do Poder Judiciário é mero reflexo dessa estrutura. ${ }^{32}$ Sua participação é exigida em múltiplos contextos em que o custo político para a tomada de uma decisão no Congresso é muito alto; em situações em que é, então, chamado a agir, no tempo adequado, a partir de critérios delimitados pelo poder representativo. Nesse ponto, não se pode afirmar que o Poder Judiciário atua exclusivamente na defesa dos direitos das minorias, sobrepondo-se à vontade da maioria. A jurisdição constitucional inclui necessariamente atuações majoritárias e contramajoritárias. ${ }^{33}$

Conforme assinala Barry Friedman, o Poder Judiciário não é necessariamente uma instância contramajoritária e, portanto, não é sistematicamente menos majoritário que as instâncias políticas. ${ }^{34} \mathrm{O}$ próprio conceito de majoritarismo é problemático e não pode servir como ponto de partida para comparação, pois a premissa de que as instâncias eleitas democraticamente são, de fato, representativas da voz da maioria pressupõe que: i. há uma vontade majoritária identificável; ii. há fidelidade na representação desta através dos

\footnotetext{
latinoamericanas: la corrupción y el clientelismo" (JARAMILLO, Leonardo García. ¿Cómo pensar hoy la tensión entre constitucionalismo y democracia? Una perspectiva desde el constitucionalismo democrático. Revista da Faculdade de Direito - UFPR, Curitiba, v. 60, n. 2, maio/ago. 2015, p. 68). Corinna Lain arremata que "Money talks. And where money talks to elected officials, elected officials are prone to listen". (LAIN, Corinna Barrett. op. cit., p. 151).

${ }^{29}$ Barry Friedman destaca que: "agenda setting is a problem, for individuals as well as in the public sphere. Some people feel so strongly about issues such as abortion that they choose their representatives on that basis alone. For many of us, however, representatives represent a variety of views and we vote on the bundle" (FRIEDMAN, Barry. op. cit., 1993, p. 639).

${ }^{30}$ Nas palavras do autor, “(...) los progresos alcanzados en la democracia electoral no han contribuido con el desarrollo de una democracia real, es decir, una democracia donde se garantizan derechos políticos mínimos (voto, oposición, pluralidad partidista, división de poderes y un sistema de frenos y contrapesos que opere razonablemente bien)". (JARAMILLO, Leonardo García. op. cit., p. 68).

${ }^{31}$ JARAMILLO, Leonardo García. op. cit., p. 67 e 95.

${ }^{32}$ RODRIGUEZ, José Rodrigo. op. cit., p. 130.

${ }^{33}$ BARROSO, Roberto. op. cit., p. 36

${ }^{34}$ Para o autor, "Courts are not systematically less majoritarian than the political branches". (FRIEDMAN, Barry. op. cit., 1993, p. 582).
}

Cadernos do Programa de Pós-Graduação em Direito PPGDir./UFRGS | Edição Digital | Porto Alegre | Volume XII | Número 2 | 2017 | P. 281 - 306 


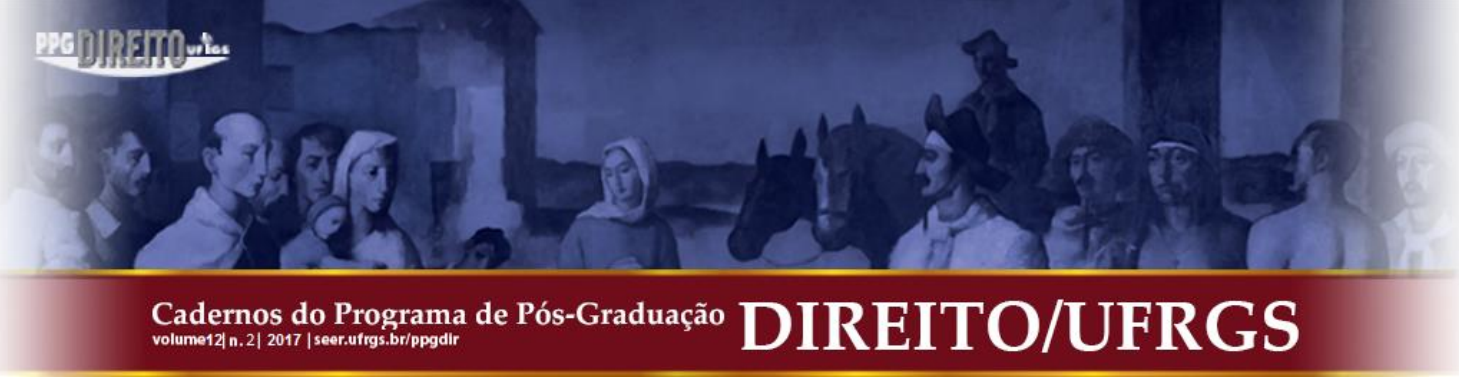

representantes eleitos; e iii. que os constituintes originários projetaram a democracia constitucional para atender a regra da maioria - o que, na realidade, nem sempre se efetiva.

Os últimos dois axiomas já se encontram superados: a vontade dos representantes eleitos não se identifica por completo com a vontade dos eleitores e a abertura do texto constitucional comporta interpretações variáveis. ${ }^{35} \mathrm{~A}$ isso, acrescente-se não ser possível extrair uma vontade majoritária ou uma voz uniforme do povo, tendo em vista que maiorias surgem e desaparecem de acordo com o desenvolvimento do debate público. Para Friedman, na melhor das hipóteses, há uma constante mudança na opinião pública. ${ }^{36}$

A dificuldade contramajoritária, assim sendo, falha no ponto em que pressupõe uma vontade majoritária estática, quando na realidade esta é fluída e dinâmica, tendo em vista que nossas preferências não são binárias, mas extremamente relativas e influenciadas por fatores diversos. ${ }^{37}$ Além de nossas preferências individuais se alterarem por inúmeros motivos, por vezes nossas preferências são acomodadas, isto é, podemos decidir aceitar a "segunda melhor decisão" por crer ser o melhor que podemos alcançar.

Em que característica, então, residiria a legitimidade do controle de constitucionalidade? Apesar de os juízes, em geral, não serem eleitos por voto popular, os ministros das Cortes Supremas via de regra são indicados por representantes populares e em diversos casos por determinado período de tempo, o que, para alguns, possibilita a reflexão das ideologias da vontade majoritária corrente no momento da indicação. ${ }^{38}$

\footnotetext{
${ }^{35}$ Nas palavras de Friedman, "Although one could argue that textual reliance is majoritarian, the opposite argument seems more persuasive. Most of the text is two hundred years old, and few of us alive today had any hand in changing the text to any significant extent. Moreover, to alter the text by formal amendment would require more than a majority of the citizenry. Reliance on the text of the Constitution therefore seems countermajoritarian". (FRIEDMAN, Barry. op. cit., 1993, p. 593). Por sua vez, Pasquino aponta que "the elections are not a divine judgment which sends the loser to hell. They simply give to the winners a fraction of political power they will use under the control of an umpire which can be asked to pass judgment if the minority requests it. Institutions have their own life, so they do not necessarily comply with the intentions of the framers". (PASQUINO, Pasquale. "Constitutional Adjudication and Democracy. Comparative Perspectives: USA, France, Italy." Ratio Juris, 11, 1, 1998. p. 47).

36 "Rather, majorities come and go as the public engages in debate. At best there is a constantly shifting of public opinion". (FRIEDMAN, Barry. op. cit., 1993, p. 638).

${ }^{37}$ Corinna Lain também sublinha essa advertência: "By way of definition, I use the term to describe prevailing sentiment at the national rather than local level, consistent with the scholarly discourse in which I am writing. Beyond that, identifying majority will is notoriously difficult. Public-opinion-poll data can be skewed, depending on how questions are asked. Institutional support can reflect elite, rather than popular, opinion. The same can be said of the popular press. (...) To the extent majority will exists at all - and sometimes, perhaps even often, it does not - it is the product of a confluence of forces, each contributing to a sense of consensus in its own way". (LAIN, Corinna Barrett. op. cit., p. 118).

${ }^{38}$ Isso é destacado, por exemplo, por Corinna Lain, segundo a qual "Court Justices are not elected, but the presidents who nominate them and the senators who confirm them are-and presumably these political actors 


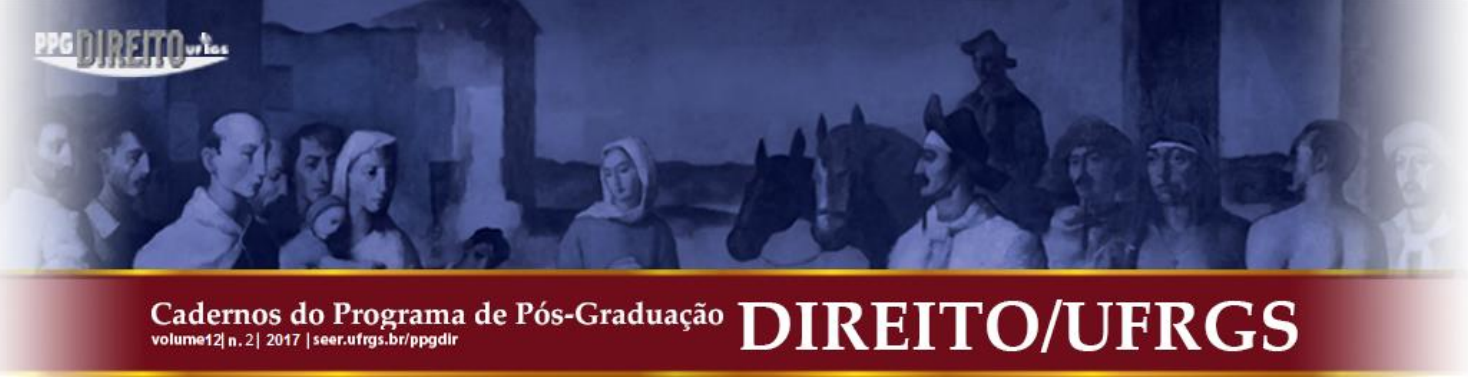

Além disso, substancialmente as decisões das Cortes também contam com legitimidade democrática na medida em que não estão, ao contrário do que se diz, imunes à pressão e controle popular. Barroso, aliás, aponta cinco fatores a partir dos quais se percebe o alinhamento da Corte com a - fluída - opinião popular, quais sejam:

i) a indicação política dos juízes, que, por isso, seriam sensíveis ao pensamento da
maioria; ii) a sujeição dos juízes aos valores da comunidade e aos mesmos
movimentos sociais; iii) a interação das Supremas Cortes com a opinião pública
(inclusive através do backlash); iv) a preocupação com sua credibilidade e
estabilidade institucional (em face das instâncias majoritárias); v) o desejo de
reconhecimento ou a preocupação com a imagem de seus integrantes junto à opinião
pública. ${ }^{39}$

Entretanto, uma vez que o legislador também está sujeito à maioria desses fatores, não são propriamente eles que fazem a diferença entre a efetiva representatividade do Legislativo e do Judiciário. ${ }^{40} \mathrm{Na}$ verdade, existem, na prática, momentos de aproximação e afastamento diante da opinião popular tanto pelo Legislativo quanto pelo Judiciário. Para Mendes o que os difere é a periodicidade fixa com que isso ocorre no Legislativo.

Tampouco se pode ignorar o fato de as decisões judiciais serem escritas para a opinião pública - ainda que em algumas jurisdições constitucionais não sejam liberados os votos dissidentes ou não se revele o debate por trás da tomada da decisão. Assim, a Corte tem consciência da necessidade de decidir, se não necessariamente para reverenciar a maioria, no mínimo, para persuadi-la. De toda forma, se a Corte desviar significativamente da vontade popular ou da deliberação do legislador possivelmente enfrentará substancial resistência na implementação de suas decisões, o que enfraquece o argumento de que apenas as instâncias sujeitas ao processo eleitoral periódico se submetem ao escrutínio popular.

\footnotetext{
favor the appointment of Justices with ideological leanings similar to their own and the constituents who elected them". (LAIN, Corinna Barrett. op. cit., p. 159). Além disso, frise-se que em nem todas as cortes se adota este modelo de indicação. Barry Friedman, referindo-se ao modelo norte-americano, assevera que "although federal judges are not elected, they are appointed by Presidents who stand for popular election. Judicial appointments often mirror the popular will that elected a President. (...) Moreover, the confirmation process for federal judges seems designed to ensure that judges are in the mainstream of popular views, at least insofar as the legislature is representative of the mainstream, and also to "teach" judges what those views are". (FRIEDMAN, Barry. op. cit., 1993, p. 612).

${ }^{39}$ BARROSO, Roberto. As razões sem voto. p. 41. Corinna Lain salienta que não obstante os juízes serem, como nós, produto de seu tempo, não correspondem ao homem médio da sociedade. Em suas palavras, "They are welleducated elites, predominately of the upper socioeconomic class, and their views tend to reflect that fact. Thus, it should come as no surprise that when the Supreme Court departs from mainstream public opinion, it tends to favor elite policy preferences instead". (LAIN, Corinna Barrett. op. cit., p. 164).

${ }^{40}$ BARROSO, Roberto. op. cit., p. 41.
} 


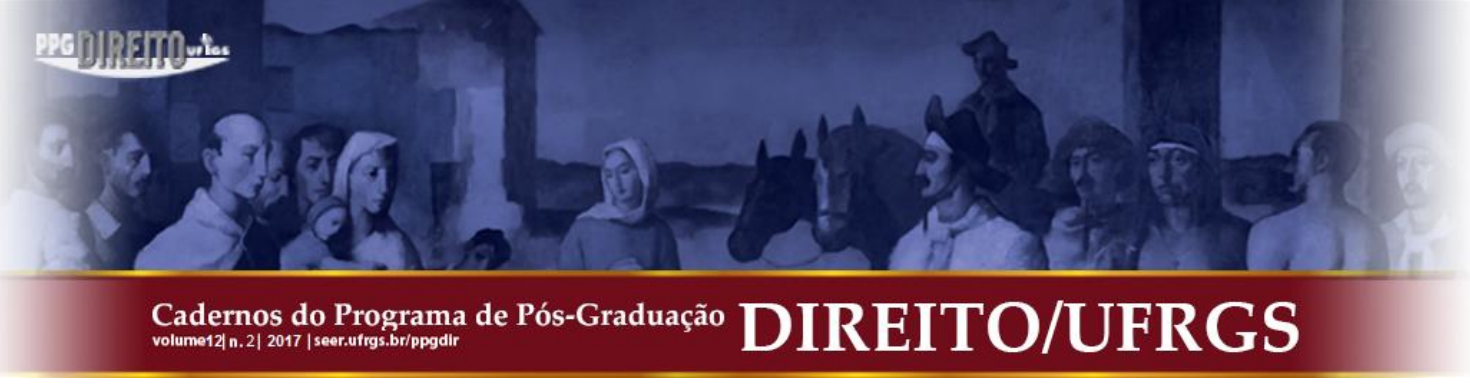

O problema da dificuldade contramajoritária também perde força ao se reconhecer que a efetividade das decisões judiciais depende de aceitação para além do âmbito judicial, e que não há uma única interpretação extraível da Constituição, tampouco um único legitimado a interpretá-la. Reconhece-se, assim, o papel da Corte como interlocutora, isto é, como instituição cuja voz é capaz de catalisar o debate que fora dela ocorre através de uma participação argumentativa e consciente da provisoriedade de sua palavra, tendo em vista o continuиm argumentativo inerente às rodadas democráticas e interações estratégicas entre os poderes. ${ }^{41}$

Além da voz da Corte, que pode e deve se modificar em caso de alteração dos valores sociais, desgaste, alteração ou equívoco na formulação de precedente ${ }^{42}$, há outros atores envolvidos no processo de construção do direito, capazes de com ela dialogar. ${ }^{43} \mathrm{O}$ Poder Judiciário atua, portanto, dentro de um contexto institucional, influenciando e sendo influenciado não apenas pelos demais poderes, mas também, por outros fatores externos e internos. Logo, não exerce a atividade jurisdicional em um vácuo institucional, isto é, em posição imune a interferências externas e até mesmo internas, verticais e horizontais. Deve, portanto, prever o comportamento dos demais atores democráticos e o resultado dos fatores envolvidos a fim de evitar a tomada de decisões que venham a ser desobedecidas ou se mostrem inefetivas.

Nessa perspectiva, Clève e Lorenzetto destacam que

Em substituição a uma leitura tradicional da separação dos poderes, a prática dos diálogos institucionais procura evidenciar pelo menos dois aspectos a respeito da formulação de decisões de casos controvertidos. Primeiro, as decisões, tomadas em qualquer um dos poderes, passam a ter um caráter parcialmente definitivo, pois, podem ser contestadas em outras instâncias públicas. Segundo, cada espaço de poder possui características que o potencializam ou o inibem para a realização de tomada de decisões. $^{44}$

\footnotetext{
${ }^{41}$ MENDES, Conrado Hübner. Deliberative Performance of Constitutional Courts. The University of Edinburgh School of Law, 2011, p. 105

42 " $E$ isso quando essas novas razões estão fundadas na alteração dos valores sociais, no desgaste do precedente na própria Corte Suprema, na alteração da concepção geral acerca do direito ou em equívoco na formulação do precedente, e, ainda, os valores da confiança justificada ou da isonomia não determinam a manutenção do precedente, preferindo-se a sinalização de que ele em breve deverá ser revogado para que não ocorrra 'supresa injusta'. (MARINONI, Luiz Guilherme. op. cit., 2013, p. 54)

43 "Despite significant structural differences, both [Poderes Legislativo e Judiciário] share, in a dynamic way, a lawmaking role (...) The curious fact of their functional redundancy, though, does not make them institutional equivalents. Their structural and procedural peculiarities forge markedly different decisional settings: they diverge in their epistemic capacities, their symbolic import, their political capital and their decisional time". (MENDES, Conrado Hübner. op. cit., 2011, p. 92).

${ }^{44}$ CLÈVE, Clèmerson Merlin; LORENZETTO, Bruno Meneses. Diálogos institucionais: estrutura e legitimidade. Revista de Investigações Constitucionais, Curitiba, v. 2, n. 3, p. 183-206, set./dez. 2015, p. 189.
} 


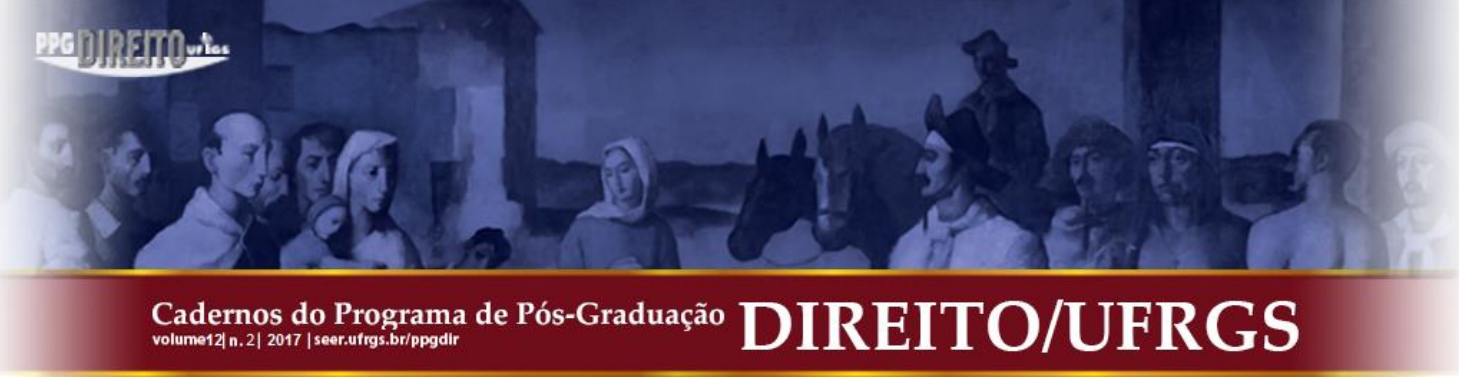

Assim, há a compreensão de que a legitimação da atividade jurisdicional está em sua capacidade argumentativa. Para John Rawls, o diferencial no modo de decidir das Cortes está no uso exemplar de razões públicas, capazes de ser compartilhadas por todos aqueles que detêm o status de cidadania e cujo conteúdo - público - inclui questões constitucionais e de justiça fundamentais. ${ }^{45}$ Apesar de o uso das razões públicas também submeter os cidadãos e os agentes políticos, o Poder Judiciário e, sobretudo, as Supremas Cortes, têm para o autor um dever exemplar no emprego de tais razões. ${ }^{46}$ Isso porque devem, além de evitar a corrosão do direito pela legislação de maiorias transitórias, desenvolver a melhor interpretação possível da Constituição a partir de seus conhecimentos sobre o que a Constituição e os precedentes exigem e de uma justificação em termos de uma concepção pública de justiça à qual todos os cidadãos, racionalmente, podem razoavelmente ser esperados a endossar. Nessa perspectiva, o papel do tribunal é ser um centro de controvérsia capaz de atribuir vivacidade às razões públicas e vitalidade ao fórum público, obrigando a discussão política a tomar forma de princípios, o que, aliás, contribui para educar os cidadãos sobre questões constitucionais básicas. ${ }^{47}$

Ronald Dworkin também fundamenta a legitimidade da Corte na sua capacidade de tratar das questões mais fundamentais da moralidade política como questões de princípio, protegidas diante do jugo político, não apenas quando chegam à Corte, mas também nos períodos que antecedem e sucedem à atividade jurisdicional. ${ }^{48} \mathrm{Em}$ outras palavras, para ele, a independência política e a responsividade a mudanças da opinião e princípios públicos ${ }^{49}$ torna a Corte a instância mais adequada à proteção de direitos do que as entidades políticas, corroídas por contra-incentivos.

\footnotetext{
45 "Public reason, then, is public in three ways: as the reason of citizens as such, it is the reason of the public; its subject is the good of the public and matters of fundamental justice; and its nature and content is public, being given by the ideals and principles expressed by society's conception of political justice, and conducted open to view on that basis". (RAWLS, John. Political Liberalism. New York: Columbia University Press, 2005, p. 213). 46 "It applies also in a special way to the judiciary and above al to a supreme court in a constitutional democracy with judicial review. This is because the justices have to explain and justify their decisions as based on their understanding of the constitution and relevant statutes and precedents. Since acts of the legislative and the executive need not be justified in this way, the court's special role makes it the exemplar of public reasons". (RAWLS, John. op. cit., p. 216).

${ }^{47}$ RAWLS, John. op. cit., p. 237-240.

48 "Judicial review insures that the most fundamental issues of political morality will finally be set out and debated as issues of principle and not political power alone, a transformation that cannot succeed, in any case not fully, within the legislature itself". (DWORKIN, Ronald. A Matter of Principle. Cambridge: Harvard University Press, 1985. p. 70). "It forces political debate to include argument over principle, not only when a case comes to the Court but also long before and long after". (idem).

${ }^{49}$ MENDES, Conrado Hübner op. cit., 2013, p. 105.
} 


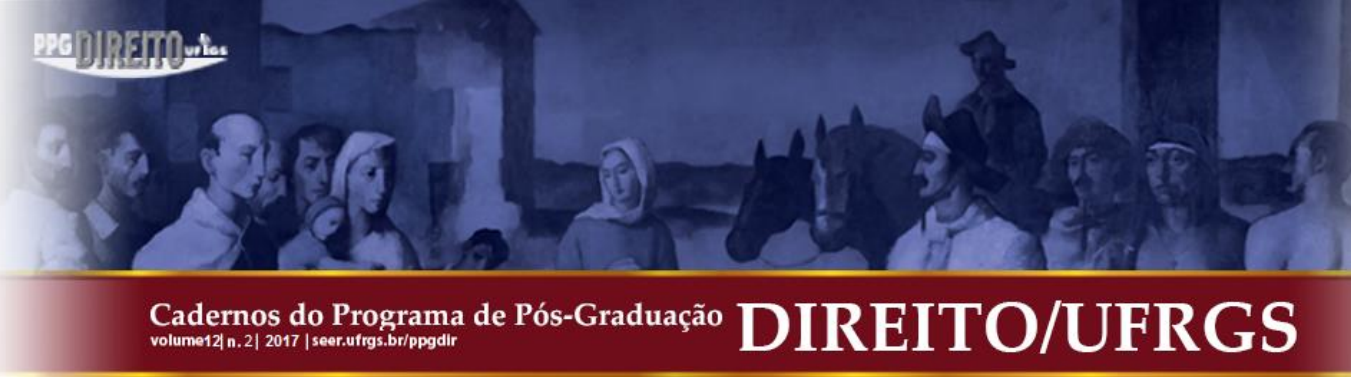

Assim, apesar de não contar procedimentalmente com legitimação eleitoral, a legitimidade seria evidenciada ex post através da tomada de decisões baseadas em princípios, cujo objeto é a proteção dos direitos individuais e cujo fundamento é a teoria substantiva da representação, segundo a qual todos devem ser tratados como iguais. Isso porque para Dworkin a democracia não se resume ao governo da maioria, dividindo-se em uma dimensão política responsável pela proteção de interesses coletivos - e uma dimensão principiológica - na qual se insere a proteção aos direitos individuais. Para o autor, enquanto a primeira deve ser resolvida nas instâncias políticas, a segunda o deve pelos tribunais constitucionais na qualidade de trunfos em face de decisões políticas de maiorias circunstanciais. ${ }^{50}$

A partir disso, Luís Roberto Barroso aponta que a Corte é a guardiã das promessas constitucionais em razão da "sua capacidade de ser um fórum de princípios — isto é, de valores constitucionais, e não de política - e de razão pública - isto é, de argumentos que possam ser aceitos por todos os envolvidos no debate". ${ }^{51}$ A democracia contemporânea, com efeito, não se limita ao governo da maioria, exigindo, segundo Barroso, além de votos, direitos e razões. ${ }^{52}$ Para o autor, a democracia consiste na integração de uma dimensão formal referente à política majoritária, uma dimensão substantiva e protetiva dos direitos fundamentais e outra deliberativa, na qual se realizam debates através de argumentos e persuasão.

Esta última dimensão, no entanto, é geralmente menosprezada. Tanto a legitimação das Cortes baseada na sua capacidade institucional de diálogo quanto aquela construída a partir de seu compromisso em fornecer as melhores razões não desenvolvem suficientemente a dinâmica interna através da qual a Corte, na qualidade de instituição colegiada, constrói sua decisão. A dimensão discursiva da democracia, exercida pela representação argumentativa, torna-a propriamente deliberativa e espera, dos julgadores, uma efetiva participação na discussão das questões sobre as quais o raciocínio decisório do colegiado está absorto. Tendo isso em vista, é imprescindível o aprofundamento da deliberação, visto que esta é responsável não apenas pela

\footnotetext{
${ }^{50}$ SILVA, Virgílio Afonso da. O STF e o controle de constitucionalidade: deliberação, diálogo e razão pública. Revista de direito Administrativo, v. 250, 2009, p. 204

${ }^{51}$ BARROSO, Roberto. op. cit., p. 37.

52 “Além do momento da investidura, o poder se legitima, também, por suas ações e pelos fins visados. Cabe retomar a ideia de democracia deliberativa, que se funda, precisamente, em uma legitimação discursiva: as decisões políticas devem ser produzidas após debate público livre, amplo e aberto, ao fim do qual se forneçam as razões das opções feitas, por isso tem-se afirmado, anteriormente, que a democracia contemporânea é feita de votos e argumentos." (BARROSO, Roberto. op. cit., p. 40).
} 


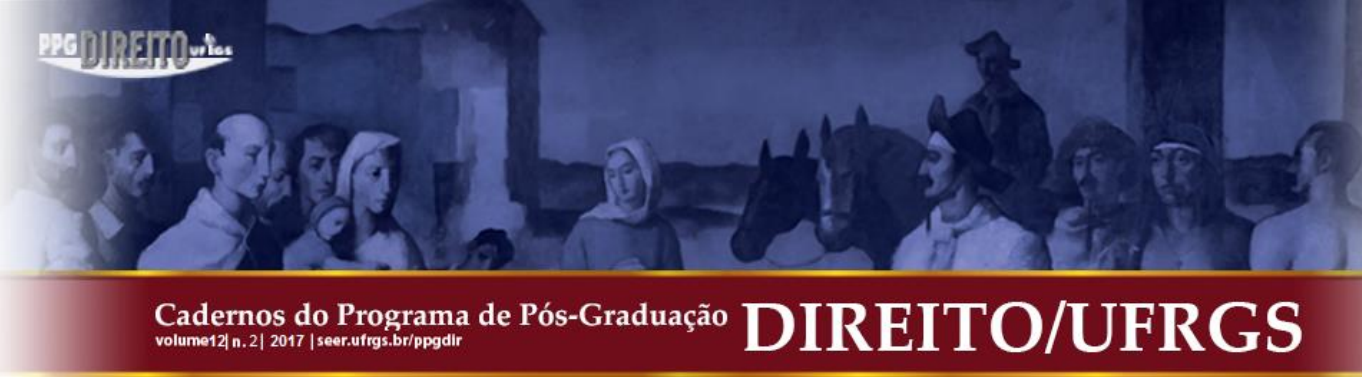

resolução dos casos concretos, mas pela legitimação das Cortes Supremas, cuja função é, em essência, a orientação prospectiva do direito. ${ }^{53}$

\section{CORTES SUPREMAS COMO "DELIBERADORES INTERNOS": A DELIBERAÇÃO EM UM TRIBUNAL COLEGIADO}

Como visto, os defensores do controle de constitucionalidade normalmente se valem do potencial deliberativo das Cortes para justificá-lo. Por outro lado, seus críticos argumentam que tal potencial, se não irrelevante, tende a ser muito fraco. ${ }^{54} \mathrm{~A}$ ideia de que as Cortes se legitimam por sua capacidade argumentativa ou ainda por seu potencial catalizador do debate interinstitucional pressupõe que o Judiciário apresenta argumentos tão somente para uma audiência externa. Ignora, no entanto, a forma como os juízes internamente se comportam, persuadem-se e apresentam suas razões entre si. ${ }^{55}$

Nesse ponto, Rawls e Dworkin, ao conceberam a capacidade argumentativa dos juízes limitada à apresentação de razões, não elaboraram como tribunais colegiados podem oscilar no exercício dessa função e como apreendê-la. ${ }^{56}$ No entender de Conrado Mendes, limitam-se a desenvolver uma teoria liberal da justiça, avaliando a legitimidade da Corte de acordo com a "acertabilidade" da decisão final: se certa ou errada, melhor ou pior, mais perto ou mais longe de seus respectivos conceitos de justiça. ${ }^{57}$ Tais teorias olvidam o fato de que os juízes não decidem sozinhos. Na realidade, em regra, apenas na instância na qual há o primeiro contato com o poder jurisdicional atua-se só e, ainda assim, a performance do julgador não pode proceder sem a consideração do sentido do direito definido deliberativamente nas Cortes Superiores.

Pode-se dizer que a visão da Corte como interlocutora acrescenta à capacidade de oferecer os melhores argumentos a aptidão de ouvir e catalizar o diálogo institucional. Porém, não basta o reconhecimento de que as Cortes são instituições colegiadas que decidem por meio

\footnotetext{
${ }^{53}$ MARINONI, Luiz Guilherme. Julgamento nas Cortes Supremas. Precedente e decisão do recurso diante do novo CPC. São Paulo: Ed. RT, 2015, p. 16.

${ }^{54}$ SILVA, Virgílio Afonso da. Deciding without deliberating. International Journal of Constitutional Law, v. 11, 2013, p. 557-584, p. 559.

55 "The public reasoner and the interlocutor supply public reasons to the external audience. Both images ignore, however, how judges internally behave and disregard whether they have simply bargained or aggregated individual positions to reach common ground". (MENDES, Conrado Hübner. op. cit., 2013, p. 102).

${ }^{56}$ MENDES, Conrado Hübner. op. cit., 2013, p. 109.

${ }^{57}$ MENDES, Conrado Hübner. op. cit., 2013, p. 109.
}

Cadernos do Programa de Pós-Graduação em Direito PPGDir./UFRGS | Edição Digital | Porto Alegre | Volume XII| Número 2 | 2017 | P. 281 - 306 


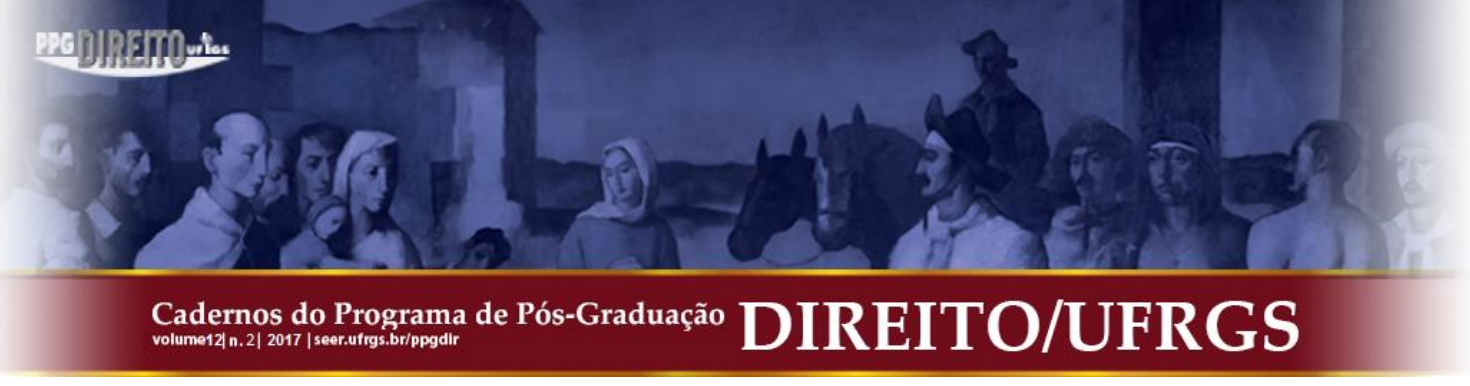

de argumentação, uma vez que cada qual lança mão de diferentes modelos de deliberação que merecem ser particularmente examinados.

Pouco se fala sobre as singularidades da dinâmica de um fórum deliberativo e de seus membros entre si. Restringe-se a elevar a Corte a um ambiente mais propício e com as melhores condições para a promoção da deliberação em razão de sua suposta imparcialidade - fruto de sua desvinculação à dinâmica eleitoral e à alternância parlamentar. ${ }^{58}$ No entanto, apesar de imparcial, o ambiente institucional das Cortes não é neutro e tampouco intrinsicamente deliberativo. Há inúmeros fatores - externos e internos - que influenciam os juízes na tomada da decisão. Aliás, há diferentes modelos explicativos acerca da tomada da decisão judicial que podem ser agrupados nos modelos legal, atitudinal e estratégico. ${ }^{59}$

Os defensores do modelo legal de comportamento judicial entendem que as decisões da Corte são substancialmente influenciadas pelos fatos do caso em questão a luz do significado literal das leis e da Constituição, da intenção do legislador originário e por precedentes. ${ }^{60}$

Por sua vez, o modelo atitudinal sustenta que os juízes decidem tão somente conforme suas respectivas ideologias e preferências políticas, de modo sincero, isto é, sob a ausência de qualquer outra influência além do seu entendimento pessoal. ${ }^{61}$ Apesar de não negar a existência de outras variáveis em jogo, como a lei e a pressão política, pressupõe não serem suficientes para penetrar o comportamento judicial. Dessa forma, prevê o resultado das votações judiciais de acordo com a predileção ideológica dos seus julgadores ${ }^{62}$ e trata a solução jurídica “como a

\footnotetext{
58 "The superficial yet widely accepted assumption that courts are special deliberative forums calls for refinement. Not much is said about what a deliberative forum entails. That contention simply stems from the institutional fact that courts are not tied to electoral behavioural dynamics, hence their impartiality, hence their better conditions to deliberate". (MENDES, Conrado Hübner. op. cit., 2013, p. 108).

59 ARGUELHES, Diego Werneck; RIBEIRO, Molhano Leandro. Preferências, Estratégias e Motivações: Pressupostos institucionais de teorias sobre comportamento judicial e sua transposição para o caso brasileiro. Revista Direito e Práxis, v. 4, n. 7, 2013, p. 90.

${ }^{60}$ Em outras palavras: "In a pure legal model, judges want only to interpret the law as well as possible. For this reason they choose between alternative case outcomes and doctrinal positions on the basis of their legal merits" (BAUM, Lawrence. Judges and Their Audiences: A perspective on judicial behavior. Princeton University Press: New Jersey, 2006, p. 5)

61 "Sincere behavior refers to a Justice acting as she would in the absence of any other influence, according to her best personal understanding" (FRIEDMAN, Barry. op. cit., 2005, p. 282). "The attitudinal model, which was the dominant model of judicial behavior among social scientists for decades, essentially posits that judges decide cases on the basis of their personal policy preferences and political ideologies - their "attitudes"' (EDWARDS, Harry. T. The effects of collegiality on judicial decision making. University of Pensilvania Law Review, 151, 5, 2003, p. 1653).

62 ARGUELHES, Diego Werneck; RIBEIRO, Molhano Leandro. op. cit., p. 91-92. A explicação do comportamento judicial através do modelo atitudinal requer a mensuração da ideologia pessoal dos juízes em uma escala ideológica liberal conservador. A forma como tal classificação deve ser feita é controvertida. Além disso, não se ignore que não basta para tanto “uma simples análise do 'mérito’ da decisão - isto é, a simples análise do

Cadernos do Programa de Pós-Graduação em Direito PPGDir./UFRGS | Edição Digital | Porto Alegre | Volume XII | Número 2 | 2017 | P. 281 - 306
} 


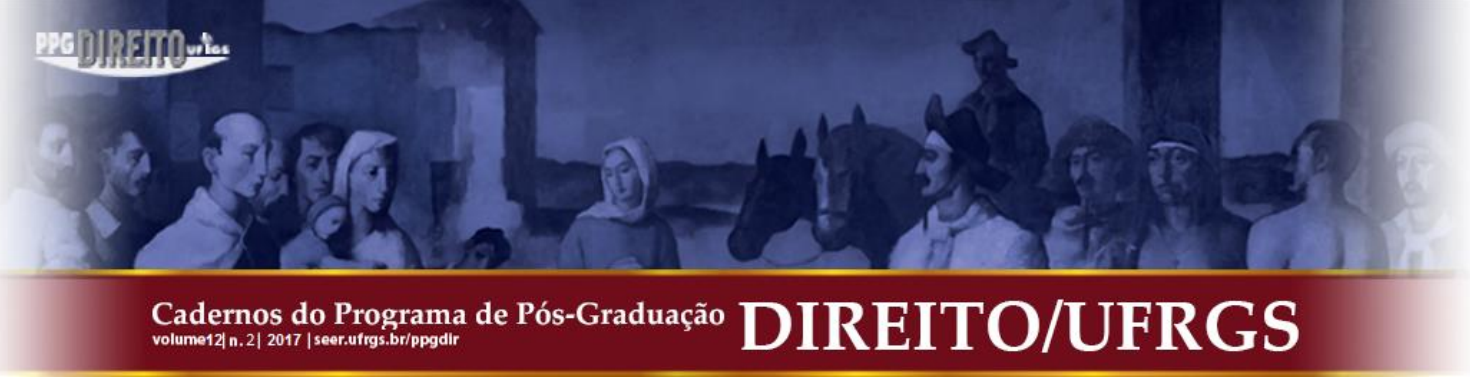

soma matemática de votos individuais quanto ao resultado, em vez de como declarações do que a lei é". ${ }^{63}$ Em outras palavras,

No modelo atitudinal (...) o direito não se configura nem como restrição, nem motivação. Ele é apenas uma racionalização ex post que justifica a tomada de uma decisão baseada em uma predisposição política do juiz (predisposição esta mensurável através de sua ideologia pessoal). ${ }^{64}$

Em outro sentido, as teorias estratégicas do comportamento judicial argumentam que os juízes se encontram constrangidos por outros fatores decisivos, isto é, que integram um determinado desenho institucional e, por isso, levam em conta o comportamento dos demais agentes - internos e externos - com os quais interagem no momento de decidir, ${ }^{65}$ bem como suas possíveis reações. Nesse horizonte, encontram-se os neoinstitucionalistas, para os quais as Cortes devem ser vistas como instituições, e não como plataformas para a exibição de atitudes individuais dos juízes. ${ }^{66}$

Internamente, leva-se em conta que não obstante os juízes poderem, de fato, decidir de acordo com suas ideologias, na medida em que as Cortes Supremas são instituições colegiadas, a sua dinâmica dialógica interna pode levar seus membros a comprometer suas preferências ideológicas para maximizar metas estratégicas. Dentre elas, destaca-se a aspiração de compor a voz majoritária da Corte e, assim, influenciar o conteúdo da opinião da maioria e contribuir para a orientação dos casos futuros, e a renúncia à possibilidade de redigir uma opinião

resultado, sem olhar para as razões escritas que o sustentam" (ibidem, p. 102). Ou seja, o foco da análise deve ser a fundamentação.

63 "When it comes to the written opinion, collegial pressures almost certainly temper what judges can do. Attitudinalists, who obviously understand that the Supreme Court operates as a composite body, miss this because they treat cases as the mathematical sum of individual votes as to outcome, rather than as statements of what the law is". (FRIEDMAN, Barry. op. cit., 2005, p. 280).

${ }^{64}$ ARGUELHES, Diego Werneck; RIBEIRO, Molhano Leandro. op. cit., p. 99.

65 "Strategic behavior involves acting other than sincerely, in order to ensure an ultimate outcome closest to the one the Justice personally prefers. Judges on a collegial court necessarily must moderate their views to achieve consensus, but often they might do more: They might, at times, act in a manner flatly contrary to their sincere views in order ultimately to move the law in the direction they prefer". (FRIEDMAN, Barry. op. cit., 2005, p. 282). Também: "What makes the calculation strategic is the understanding that an actor's goal are a product of the interaction between his or her behavior and the behavior (or anticipated behavior) of others". (GILLMAN, Howard. The Court as an Idea, not a Building (or a game): interpretive institutionalism and the analysis of Supreme Court Decision-Making. In: CLAYTON, C. W.; GILLMAN, H. (Eds.). Supreme Court Decision-Making: new institutionalist approaches. Chicago: The University of Chicago Press, 1999, p. 68).

66 "There is one other social science model that seeks to shed light on judicial decision making: "new institutionalism.' The proponents of this model treat courts as institutions rather than as platforms for the display of individual [udges'] attitudes." (EDWARDS, Harry. T. op. cit., p. 1662). 


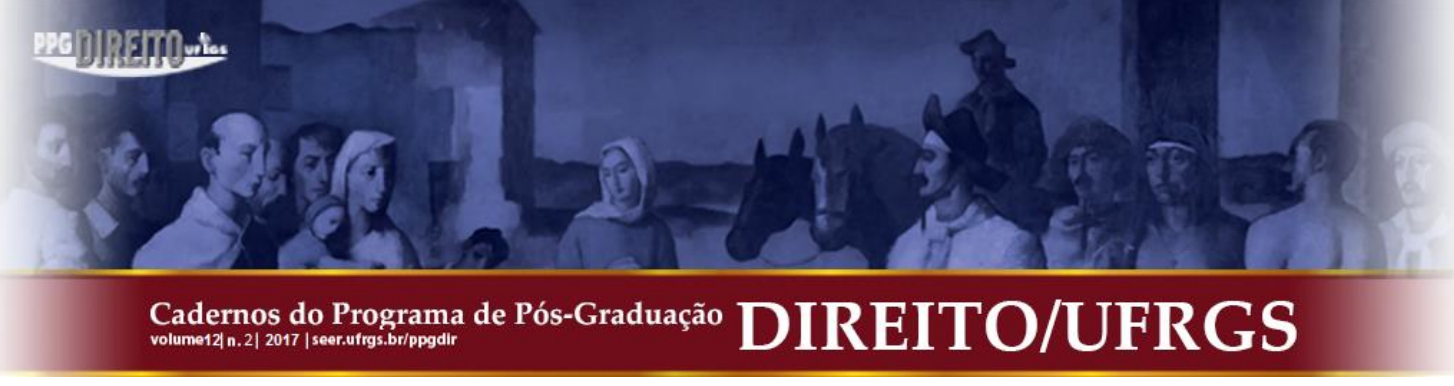

dissidente. ${ }^{67}$ Os juízes também podem ser motivados pelo respeito aos precedentes, ${ }^{68}$ pelos interesses de consolidar o poder nacional, de proteger a independência da Corte, de evitar eventual impeachment, de promover a agenda política de alguma classe ou coalizão dominante ou, ainda, até mesmo pela ambição de concorrer, futuramente, a algum cargo político. ${ }^{69}$

A partir deste ponto de vista, a análise dos efeitos institucionais sobre a tomada de decisão reside na verificação da influência da relação entre as atitudes e o comportamento dos atores com a missão institucional por eles discernida. ${ }^{70}$ Nessa perspectiva, incorporam-se à análise da tomada de decisão experiências de dever e obrigação profissional, apreensões de propósito comum, preocupações sobre a manutenção da autoridade ou legitimidade corporativa e participação em uma rotina. ${ }^{71}$ Com efeito, quando os membros de uma Corte partilham da concepção de uma missão institucional, os interesses e as preferências não judiciais incompatíveis com as funções da instituição (como fins pessoais) são por ela filtrados.

Sob uma perspectiva externa, a Corte sofre influências de outros agentes quando estes têm o poder de "a) vetar ou reverter suas decisões judiciais; b) ameaçar a credibilidade do tribunal ou dos juízes; ou c) retaliar contra o tribunal ou os juízes individualmente". ${ }^{72}$ A partir disso, é possível que os juízes acomodem suas preferências a fim de evitar conflitos e sobretudo - não frustrar a missão institucional da Corte. ${ }^{73}$

\footnotetext{
67 "The strategic model does not reject the possibility that judges act in accordance with their personal ideologies; rather, it focuses on panel composition and presumed interactions among judges in an attempt to determine how judges influence one another in decision making. Under this model, a judge's vote may not always reflect his or her "sincere" ideological preferences, because the internal dynamics of the panel may lead judges to compromise their ideological preferences to maximize "strategic" goals-such as being in the majority, influencing the content of the majority opinion, avoiding writing a dissent, or building capital for future cases". (EDWARDS, Harry. T. op. cit., p. 1653).

68 "O modelo dos autores aceita as premissas do modelo atitudinal e estratégico, mas incorpora o direito como uma restrição importante à maximização das preferências dos juízes por policies. A variável explicativa é a obediência, por parte dos Ministros da Corte, aos precedentes da própria instituição". (ARGUELHES, Diego Werneck; RIBEIRO, Molhano Leandro. op. cit., p. 104).

${ }^{69}$ GILLMAN, Howard. op. cit., p. 76.

70 "From this point of view, to examine institutional effects on decision-making is, in part (the part that parallels the "intra-court bargaining" side of the strategic approach), to determine whether institutional actors are influenced in their attitudes and behavior by their relationship to their institution's mission and to the organizational attributes that have been constructed in service of that mission". (GILLMAN, Howard. op. cit., p. 79).

71 "When we move beyond viewing institutions as facilitating or impeding self-interested behavior we are able to incorporate: experiences of duty and professional obligation, understandings of shared purpose, concerns about the maintenance of corporate authority or legitimacy, and participation in a routine - each of which suggests the presence of a kind of motivation that is something other than rational, self-interested, strategic, and calculating". (GILLMAN, Howard. op. cit., p. 84)

${ }^{72}$ ARGUELHES, Diego Werneck; RIBEIRO, Molhano Leandro. op. cit., p. 100.

73 "The strategic approach assumes that justices will bargain or retreat in the face of a challenge or will adopt insincere positions on the merits in order to aviod a conflict with powerholders who are in a position to thwart the will of the Court". (GILLMAN, Howard. op. cit., p. 69).
} 


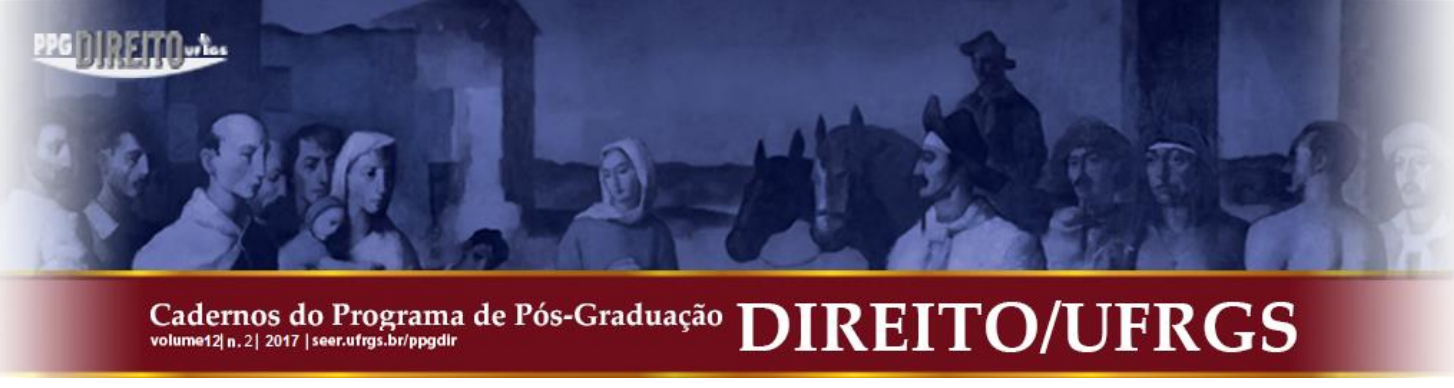

Nesse ponto, Friedman destaca que os círculos concêntricos de influência e constrangimento com os quais um juiz constitucional deve lidar incluem, além da interação estratégica com seus colegas, internamente, as pressões impostas pelos juízes de hierarquia inferior, as eventuais futuras reações dos Poderes Legislativo e Executivo - seja por meio de emendas constitucionais ou decretos provisórios, por exemplo -, e a opinião popular. ${ }^{74}$

Ainda, para a preservação da sua integridade institucional, a Corte, por fazer parte de um ambiente institucional heterogêneo, deve assegurar a concretização de suas ordens pelos demais agentes com quem interage através da percepção dos sinais por eles emitidos e, assim, do cálculo da sua futura reação e dos eventuais constrangimentos aos quais está submetida. ${ }^{75}$ Dentre eles, Friedman destaca que além de os juízes poderem sofrer impeachment, a jurisdição pode ser desaparelhada, as Cortes, insuladas, e o orçamento judicial, cortado. ${ }^{76}$

Observe-se, porém, que o processo deliberativo não comporta uma resposta binária, não sendo possível, portanto, a adjetivação precisa de suas respostas como "sinceras" ou “estratégicas". ${ }^{77}$ Trata-se de um diálogo complexo e concatenado por uma sequência de atos no qual os juízes devem construir conjuntamente um resultado coletivo, ainda que não unânime, diverso daquele ao qual chegariam se estivessem a decidir sozinhos. ${ }^{78}$ Para tanto, como as Cortes não são agentes intrinsicamente deliberativos, ${ }^{79}$ para que seja possível a efetivação do debate em um tribunal colegiado pressupõe-se, além de um desenho institucional favorável, o compartilhamento de um ideal de deliberação e de uma concepção de papel institucional. Devese partilhar, também, uma mesma ética de deliberação, isto é, os mesmos valores deliberativos.

Segundo Conrado Mendes, a performance deliberativa da Corte é consequência de uma complexa interação entre dispositivos institucionais, os traços éticos dos deliberadores, os

\footnotetext{
74 "The fear of a public backlash can be a forceful inducement to implement judicial decisions faithfully". (FRIEDMAN, Barry. op. cit., 2005 p. 324).

${ }^{75}$ FRIEDMAN, Barry. op. cit., 2005, p. 315-316.

${ }^{76}$ FRIEDMAN, Barry. op. cit., 2005, p. 313-314.

77 "Three features of collegial adjudication complicate the analysis of strategic behavior in the context of multijudge courts. First, in deference to their colleagues, appellate judges are expected to compromise or deflect their views to some extent. Second, adjudication, unlike the voting paradigm in game theory, involves the rendering of judgments rather than the expression of preferences. Finally, judges often decide controversies that raise more than one issue; indeed, in paradoxical cases they are always called on to do so. The simple line between strategic and sincere behavior seems inapt to multi-judge courts, where, as we have seen, the decisionmaking process is collegial and it is the norm for judges to sacrifice details of their convictions in the service of producing an outcome and opinion attributable to the court." (KORNHAUSER, Lewis; SAGER, Lawrence. The One and the Many: Adjudication in Collegial Courts. California Law Review, 81, 1, 1993, p. 52)

${ }^{78}$ EDWARDS, Harry. T. The effects of collegiality on judicial decision making. p. 1660.

79 "A collegiate court is not, in and of itself, a deliberative body. I submit, nonetheless, that there are good reasons for courts to espouse that aspirational practice”. (MENDES, Conrado Hübner. op. cit., 2011, p. 74). 


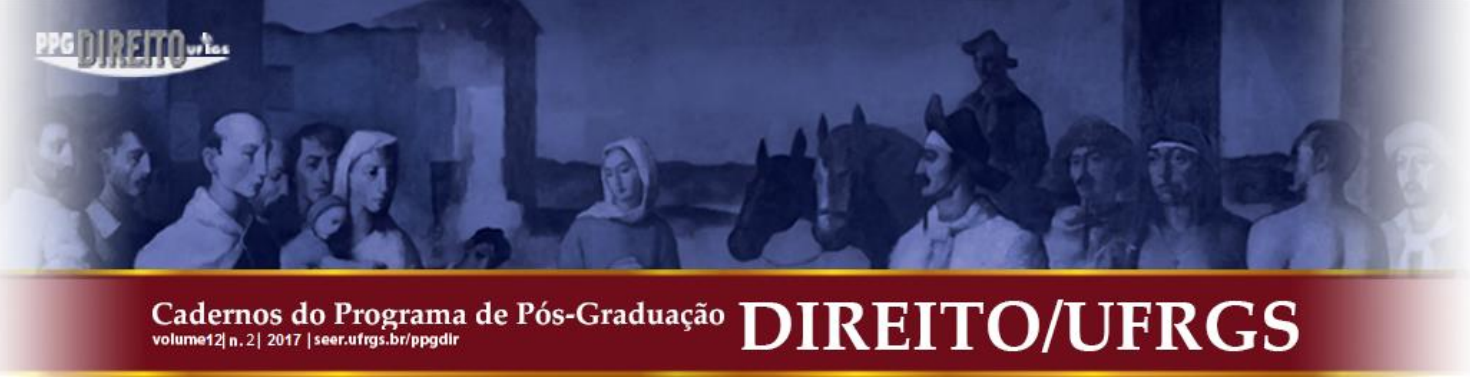

materiais legais e o cenário político. ${ }^{80}$ Para ele, deliberação inclui a presunção de igualdade entre os participantes, a exibição clara de respeito e a ausência de coerção, isto é, de argumentação interpessoal resguardada de interesses egoístas, caracterizando-se pela tolerância diante de desacordos remanescentes quando esgotado o horizonte argumentativo. ${ }^{81}$ Assim, deliberadores devem ser propensos não apenas a falar, mas também a ouvir, e estar dispostos a mudar suas preferências originais à luz dos novos argumentos levantadas durante a discussão. ${ }^{82}$ Para ele, deliberação política é um processo de tomada de decisão exigente através do qual razões de um tipo específico são trocadas na tentativa de persuadir e chegar a um consenso. ${ }^{83}$

A decisão tomada de modo deliberativo necessariamente afeta aqueles que estão deliberando; não é considerada como final, e sim como ponto de partida provisório a ser sucedido por novas rodadas deliberativas; é uma prática argumentativa coletiva e de justificação diante dos demais membros; caracteriza-se pela exposição de razões particulares, isto é, imparciais ou ao menos traduzíveis para o bem comum; pela capacidade de motivar os deliberadores a revisar e alterar suas opiniões originárias e de conceber uma "ética de consenso"; é capaz de inspirar uma elemento ético de respeito, segundo o qual todos merecem ser tratados com igual consideração, compreendendo, portanto, um compromisso político de inclusão, empatia e a responsividade a todos os pontos de vista. ${ }^{84}$

Harry Edwards define a deliberação entre juízes como um processo de diálogo, persuasão e revisão, em que se desenvolve uma familiaridade entre suas respectivas inclinações, formas de pensar e padrões de argumentação até se chegar ao ponto de ser possível antecipar as posições uns dos outros. ${ }^{85}$ Por sua vez, Ferejohn e Pasquino caracterizam a deliberação como

\footnotetext{
80 "Deliberative performance, therefore, is the consequence of a complex interaction between the institutional devices, the ethical traits of deliberators, the legal materials and the political landscape". (MENDES, Conrado Hübner. op. cit., 2011, p. 122).

${ }^{81}$ No entanto, há tribunais nos quais se exige o consenso, o que constrange muitas vezes seus membros a acomodar suas posições. É o caso da Corte Costituzionale Italiana, por exemplo.

82 "Deliberation denotes absence of coercion, inter-personal argumentation detached from egotistic interests, tolerance towards enduring disagreement after the exhaustion of the argumentative horizon, presumption of equal status among participants and clear display of respect. Deliberators are prone both to listen and to speak, and are disposed to change their previous preferences in the light of the new arguments that are raised during discussion". (MENDES, Conrado Hübner. op. cit., 2011, p. 141).

${ }^{83}$ Nesse sentido: "Political deliberation is a demanding decision-making process through which reasons of a specific kind are exchanged in the attempt to persuade and reach consensus". (MENDES, Conrado Hübner. op. cit., 2011, p. 124).

${ }^{84}$ MENDES, Conrado Hübner. op. cit., 2011, p. 22-26

85 "Deliberations among judges are characterized more accurately as a process of dialogue, persuasion, and revision. To be sure, judges do develop a familiarity with their colleagues' inclinations, habits of mind, and patterns of reasoning. Over time, they may be able to anticipate how colleagues will approach issues". (EDWARDS, Harry. T. op. cit., p. 1661).
}

Cadernos do Programa de Pós-Graduação em Direito PPGDir./UFRGS | Edição Digital | Porto Alegre | Volume XII | Número 2 | 2017 | P. 281 - 306 


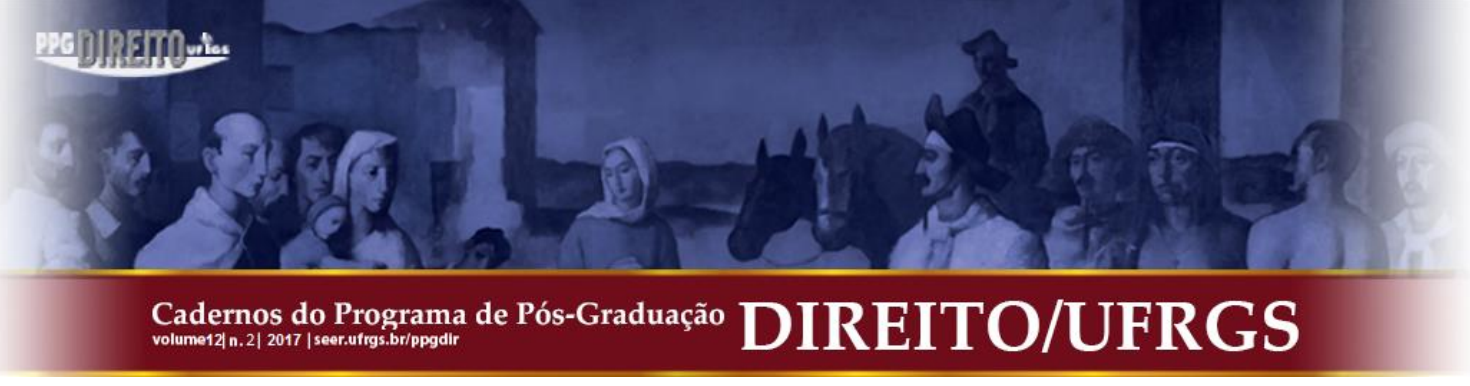

“a participação no processo de argumentação racional subjacente à atuação pública" 86 através da qual se verifica a disposição dos deliberadores em alterar suas razões originais após a troca de argumentos. ${ }^{87}$ Assim, um processo deliberativo consiste, antes de mais nada, num processo de persuasão no qual seus seus participantes estão abertos a absorver, compartilhar e revisar suas posições iniciais. Além disso, desenvolve-se a partir de uma ética do consenso subjacente ao diálogo. ${ }^{88}$

Para Kornhauser e Sager, uma forma de decidir deliberativa afeta o comportamento dos juízes em pelo menos três diferentes maneiras. Primeiramente, maior será a gama de justificativas levantadas, o que oferece aos juízes mais opções de resultado. Além disso, tal exposição de razões pode esclarecer determinados pontos e, assim, influenciar os juízes a mudar de opinião. Ou seja, a pressão colegiada pode induzir o juiz, consciente ou inconscientemente, a conformar seu entendimento àquele que seus colegas entendem como minimamente aceitável. ${ }^{89}$ Os autores chegam à conclusão de que as possíveis vantagens proporcionadas pela deliberação superam seus eventuais riscos: a ignorância a respeito de justificações úteis é mais prejudicial do que a exposição a falsas ideias ou argumentos, assim como a indicação de eventuais erros e restrições compensa a eventual supressão de argumentos originais e criativos, porém inaceitáveis perante a comunidade. ${ }^{90}$

Além do dever de os deliberadores assimilarem, implícita ou explicitamente, as diferentes opiniões apresentadas, devem realizar um exercício de imaginação e empatia quanto aos pontos de vista não expressos diretamente na discussão porque ausentes seus emissores, igualmente sujeitos ao resultado da deliberação. Também devem estar preparados para

${ }^{86}$ FEREJOHN, John; PASQUINO, Pasquale. Tribunais constitucionais como instituições deliberativas. In: BIGONHA, Antonio Carlos Alpino e MOREIRA, Luiz (Orgs.). Limites do controle de constitucionalidade. Rio de Janeiro: Lumen Juris, 2009, p. 43.

${ }^{87}$ FEREJOHN, John; PASQUINO, Pasquale. op. cit., 2009, p. 43.

${ }^{88}$ MENDES, Conrado Hübner. op. cit., 2005, p. 24

89 "Deliberation could affect the behavior of any given judge in at least three different ways. First, a judge may become more fully aware of the range of rationales for one or another possible result and, in some cases, more fully aware of possible results; in this sense her judgement set will have been expanded by deliberation. Second, deliberation may convince a judge that there are good reasons to change her mind. (...) Third, the communal pressures of deliberation may induce in a given judge a conscious or unconscious impulse to conform her judgment to a range of results that her colleagues treat as acceptable". (KORNHAUSER, Lewis; SAGER, Lawrence. Unpacking the Court. The Yale Law Journal, 96, 1, 1986, p. 101).

90 "Thus, if we favor deliberation as a means of improving group judgement, it must be because we assume that its judgment-enhancing aspects outweigh its judgment-impairing features. Our reasons may include the view that ignorance of useful ideas or arguments is a greater hazard to the capacity of reflective individuals to form correct judgments than exposure to false ideas or arguments, or the view that the deliberative process will do more good in exposing obvious errors and restraining mad acts than harm in suppressing novelty". (KORNHAUSER, Lewis; SAGER, Lawrence. op. cit., 1986, p. 102).

Cadernos do Programa de Pós-Graduação em Direito PPGDir./UFRGS | Edição Digital | Porto Alegre | Volume XII | Número 2 | 2017 | P. 281 - 306 


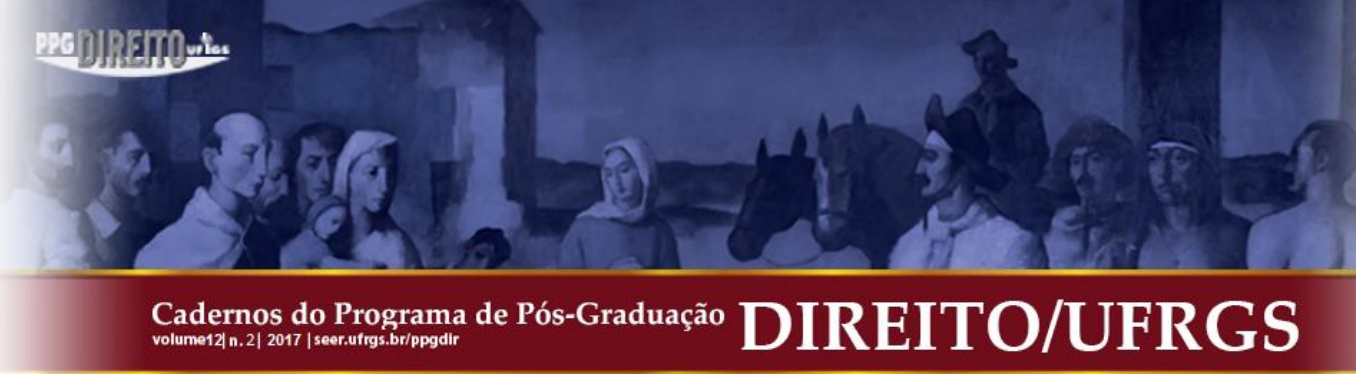

membros, de modo que aos argumentos geralmente atribuídos para legitimá-las deve ser adicionada uma perspectiva interna de análise.

Para que se justifique a revisão judicial de atos legislativos, o diálogo intrainstitucional dos membros de uma Corte deve se pautar por um ideal de deliberação, caracterizado por um ambiente de respeito mútuo, empatia e igualdade. Apesar de prescindirem do alcance de um consenso, os membros de um tribunal colegiado devem empreender um processo de persuasão capaz de reproduzir, ao final, uma voz o mais institucional possível. Além disso, devem ter em mente que o processo deliberativo é composto por sucessivas rodadas interpretativas, de modo que, além de argumentarem entre si, devem dialogar circularmente com os demais participantes presentes em seu desenho institucional.

Ainda que os benefícios da deliberação não sejam inequívocos e a interação entre juízes apresente riscos à qualidade da decisão tomada, conclui-se que o compartilhamento de uma cultura e ética deliberativa é capaz de potencializar os benefícios da deliberação e contribuir para a justificação da revisão de atos legislativos por juízes não eleitos democraticamente.

\section{REFERÊNCIAS}

ARGUELHES, Diego Werneck; RIBEIRO, Molhano Leandro. Preferências, Estratégias e Motivações: Pressupostos institucionais de teorias sobre comportamento judicial e sua transposição para o caso brasileiro. Revista Direito e Práxis, v. 4, n. 7, 2013.

BARROSO, Luís Roberto. As razões sem voto. Revista Brasileira de Políticas Públicas, v. 5, Número Especial, 2015.

BAUM, Lawrence. Judges and Their Audiences: A perspective on judicial behavior. Princeton University Press: New Jersey, 2006.

BICKEL, Alexander. The Least Dangerous Branch: the Supreme Court at the Bar of Politics. New Haven: Yale University Press, 1986.

CLÈVE, Clèmerson Merlin. Presidencialismo de coalizão e administração pública. In: CLÈVE, Clèmerson Merlin (Coord.). Direito Constitucional Brasileiro: organização do estado e dos poderes. v. 2. São Paulo: Revista dos Tribunais, 2014.

CLÈVE, Clèmerson Merlin; LORENZETTO, Bruno Meneses. Constituição federal, controle jurisdicional e níveis de escrutínio. Direitos Fundamentais e Justiça, a. 9, n. 32, p. 97-123, jul./set. 2015. 


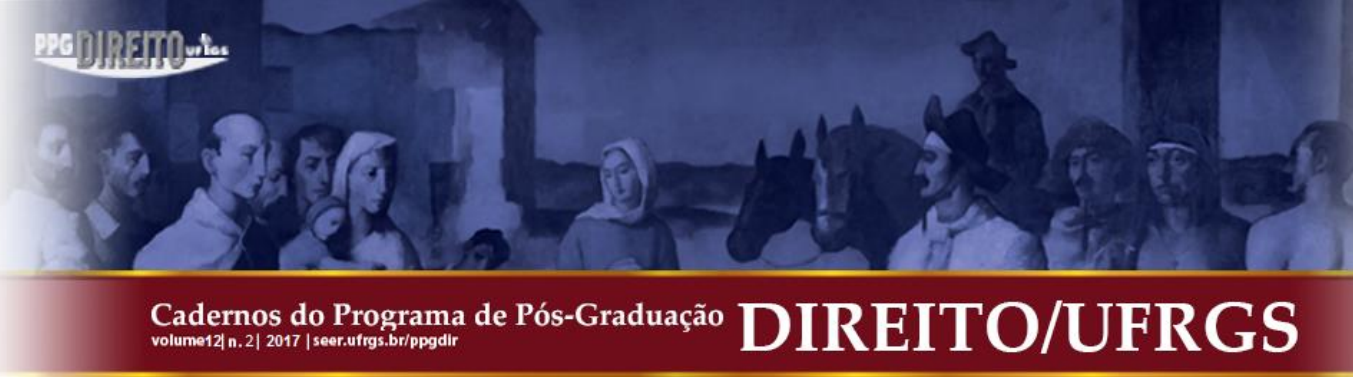

CLÈVE, Clèmerson Merlin; LORENZETTO, Bruno Meneses. Diálogos institucionais: estrutura e legitimidade. Revista de Investigações Constitucionais, Curitiba, v. 2, n. 3, p. 183206, set./dez. 2015.

CLÈVE, Clèmerson Merlin; LORENZETTO, Bruno Meneses. Interpretação constitucional: entre dinâmica e integridade. Revista Sequência, n. 72, 2016.

CLÈVE, Clèmerson Merlin; LORENZETTO, Bruno Meneses. Teorias Interpretativas, Capacidades Institucionais e Crítica. Revista Direitos Fundamentais e Democracia, v. 19, n. 19, 2016.

DWORKIN, Ronald. A Matter of Principle. Cambridge: Harvard University Press, 1985.

EDWARDS, Harry. T. The effects of collegiality on judicial decision making. University of Pensilvania Law Review, 151, 5, 2003.

FEREJOHN, John; PASQUINO, Pasquale. Constitutional Adjudication: Lessons From Europe. Texas Law Review, 82, 2004.

FEREJOHN, John; PASQUINO, Pasquale. Tribunais constitucionais como instituições deliberativas. In: BIGONHA, Antonio Carlos Alpino e MOREIRA, Luiz (Orgs.). Limites do controle de constitucionalidade. Rio de Janeiro: Lumen Juris, 2009.

FRIEDMAN, Barry. Dialogue and Judicial Review. Michigan Law Review, 91, 1993.

The politics of judicial review. Texas Law Review, 84, 2, 2005.

GILLMAN, Howard. The Court as an Idea, not a Building (or a game): interpretive institutionalism and the analysis of Supreme Court Decision-Making. In: CLAYTON, C. W.; GILLMAN, H. (Eds.). Supreme Court Decision-Making: new institutionalist approaches. Chicago: The University of Chicago Press, 1999.

HAMILTON, A.; MADISON, J.; JAY, J. The Federalist Papers. New York: Signet Classics, 2003.

JARAMILLO, Leonardo García. ¿Cómo pensar hoy la tensión entre constitucionalismo y democracia? Una perspectiva desde el constitucionalismo democrático. Revista da Faculdade de Direito - UFPR, Curitiba, v. 60, n. 2, maio/ago. 2015.

KORNHAUSER, Lewis; SAGER, Lawrence. The One and the Many: Adjudication in Collegial Courts. California Law Review, 81, 1, 1993.

KORNHAUSER, Lewis; SAGER, Lawrence. Unpacking the Court. The Yale Law Journal, 96, $1,1986$. 


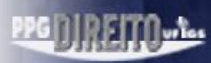

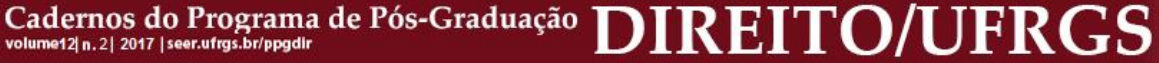

TARUFFO, Michele. Processo civil comparado: Ensaios. São Paulo: Marcial Pons, 2013.

Submissão: 15/04/2017

Aceito para Publicação: 11/12/2017 
